\title{
Significantly Enhanced Overall Water Splitting Performance by partial oxidation of Ir through Au Modification in Core-shell Alloy Structure
}

Huimin Wang, ${ }^{+, \neq}$Zhe-ning Chen, ${ }^{+}$Dongshuang Wu, ${ }^{\perp}$ Minna Cao, ${ }^{+, \neq *}$ Fanfei Sun, ${ }^{\S, \neq}$ Hao Zhang, ${ }^{\S, \neq}$ Hanhui You, ${ }^{\dagger}$ Wei Zhuang ${ }^{+*}$ and Rong Cao ${ }^{+, \neq *}$

†State Key Laboratory of Structural Chemistry, Fujian Institute of Research on the Structure of Matter, Chinese Academy of Sciences, Fuzhou, 350002, P. R. China

${ }^{\perp}$ Division of Chemistry, Graduate School of Science, Kyoto University, Kyoto 6o6-8502, Japan

\$Shanghai Synchrotron Radiation Facility, Shanghai Institute of Applied Physics, Chinese Academy of Sciences, Shanghai, 201204, P. R. China

‡University of Chinese Academy of Sciences, Beijing, 100049, P. R. China

\section{Table of contents}

1. Materials and Methods .......................................................................2

2. Characterizations and Electrochemical Measurements ................................3

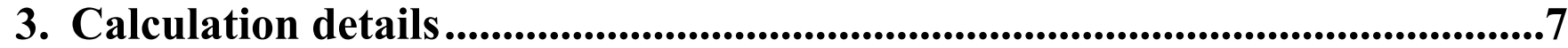

4. Supplementary Figures and Tables..................................................................10

5. References 


\section{Materials and Methods}

1.1 Materials. Hydrogen tetrachloroaurate (III) trihydrate $\left(\mathrm{HAuCl}_{4} \cdot 3 \mathrm{H}_{2} \mathrm{O}, 99.9 \%\right)$ and 5 wt $\%$ Nafion solution ( $\sim 5 \%$ in lower aliphatic alcohols and water, contains $15-20 \%$ water) were purchased from Sigma-Aldrich. Iridium (III) Chloride Hydrate $\left(\mathrm{IrCl}_{3} \cdot \mathrm{xH}_{2} \mathrm{O}, 99.9 \%\right)$ and Iridium (IV) oxide powder $\left(\mathrm{IrO}_{2}, 99 \%\right)$ were purchased from Alfa Aesar. Oleylamine (80.0-90\%) was purchased from Acros. Carbon black (Vulcan XC-72), commercial Pt/C (20\% Pt on Vulcan $\mathrm{XC}-72)$ and commercial $\mathrm{Ir} / \mathrm{C}(20 \% \mathrm{Ir}$ on Vulcan XC-72) were purchased from Premetek. Cyclohexane $\left(\mathrm{C}_{6} \mathrm{H}_{12}\right.$, A.R.), hexane $\left(\mathrm{C}_{6} \mathrm{H}_{14}\right.$, A.R.), acetone $\left(\mathrm{C}_{3} \mathrm{H}_{6} \mathrm{O}\right.$, A.R. $)$, ethanol $\left(\mathrm{C}_{2} \mathrm{H}_{5} \mathrm{OH}\right.$, A.R.), and iso-Propyl alcohol $\left(\mathrm{C}_{3} \mathrm{H}_{8} \mathrm{O}\right.$, A.R.) were purchased from Sinopharm Chemical Reagent Co. Ltd. All the chemicals were used as received without further purification. The water used in all experiments was ultrapure (Millipore, $18.25 \mathrm{M} \Omega / \mathrm{cm}$ ).

1.2 Synthesis of $\mathbf{A u @ A u I r} \mathbf{I r}_{2}$ : In a typical synthesis of $\mathrm{Au} @ \mathrm{AuIr}_{2}, 0.1334 \mathrm{mmol} \mathrm{HAuCl}_{4} \cdot 3 \mathrm{H}_{2} \mathrm{O}$ and $0.0667 \mathrm{mmol} \mathrm{IrCl}_{3} \cdot \mathrm{xH}_{2} \mathrm{O}$ were dissolved in $10 \mathrm{~mL}$ oleylamine by ultrasonicating several minutes to form a solution. And then the mixture was put into a preheated metal bath, magnetically stirred, and heated at $220{ }^{\circ} \mathrm{C}$ for $3 \mathrm{~h}$ under nitrogen atmosphere. After the flask cooled to room temperature, the brown products were centrifuged with inputting ethanol at $10000 \mathrm{rpm}$ for $5 \mathrm{~min}$, and then washed by using a mixture of ethanol/cyclohexane/acetone 8 times. Finally as-synthesized $\mathrm{Au} @ \mathrm{AuIr}_{2}$ was re-dispersed in cyclohexane for reserve.

1.3 Synthesis of Au nanoparticles (Au NPs): In a typical synthesis of Au nanoparticles, $0.2 \mathrm{mmol}$ $\mathrm{HAuCl}_{4} \cdot 3 \mathrm{H}_{2} \mathrm{O}$ was dissolved in $15 \mathrm{~mL}$ oleylamine by ultrasonicating several minutes to form a solution. And then the mixture was put into a preheated metal bath, magnetically stirred, and heated at $180{ }^{\circ} \mathrm{C}$ for $30 \mathrm{~min}$ under nitrogen atmosphere. After the flask cooled to room temperature, the purple products were centrifuged with inputting ethanol at $10000 \mathrm{rpm}$ for 5 min, and then washed by using a mixture of ethanol/cyclohexane/acetone 8 times. Finally as-synthesized Au NPs were re-dispersed in cyclohexane for reserve.

1.4 Synthesis of Ir nanoparticles (Ir NPs): The experiment is as follows: $0.0667 \mathrm{mmol}$ $\mathrm{IrCl}_{3} \cdot \mathrm{xH}_{2} \mathrm{O}$ was dissolved in $10 \mathrm{~mL}$ oleylamine by ultrasonicating several minutes to form a solution. Then the mixture was put to a preheated metal bath and was kept at $280{ }^{\circ} \mathrm{C}$ for $3 \mathrm{~h}$ under a nitrogen atmosphere with stirring. 
1.5 Synthesis of C-supported Au@AuIr 2 (20 wt\% loading): To prepare our Au@AuIr electrocatalysts, we mixed and stirred a hexane dispersion of $\mathrm{Au} @ \mathrm{AuIr}_{2}$ with 20 mg Carbon black (Vulcan XC-72) for $2 \mathrm{~h}$, after which hexane was evaporated from the solution. The catalysts were washed with ethanol and dried under vacuum.

1.6 Synthesis of C-supported Au NPs (20 wt\% loading): To prepare Au electrocatalysts, we mixed and stirred a hexane dispersion of $5 \mathrm{mg}$ of Au NPs with $20 \mathrm{mg}$ Carbon black (Vulcan $\mathrm{XC}-72$ ) for $2 \mathrm{~h}$, after which hexane was evaporated from the solution. The catalysts were washed with ethanol and dried under vacuum.

\section{Characterizations and Electrochemical Measurements}

2.1 Structural Characterizations. Transmission electron microscopy (TEM), high-resolution transmission electron microscopy (HRTEM), energy dispersive X-ray spectroscopy analysis (EDS), scanning transmission electron microscopy (STEM), and STEM-EDS element mapping were conducted on Talos-F200X scanning/transmission electron microscope (S/TEM) (Thermo Scientific, America) respectively operated at $200 \mathrm{kV}$. Inductively coupled plasma atomic emission spectrometry (ICP) was performed with Ultima2 inductively coupled plasma OES spectrometer (ICP-OES, Agilent 730) to analyze the elemental composition of the materials. powder X-ray diffraction (PXRD) analysis was carried out on Miniflex-600 X-ray diffractometer (Rigaku, Japan), with scanning speed of $0.2^{\circ} / \mathrm{min}$ under $\mathrm{Cu} \mathrm{K} \alpha$ radiation $(\lambda=1.5406 \AA$ ). X-ray photoelectron spectroscopy (XPS) was conducted on X-ray photoelectron spectrometer (ESCALAB 250Xi, Thermo Fisher) with a monochromatic Al Ka (1486.7 eV) X-ray source and a chamber pressure maintained $5 \times 10^{-10}$ mbar.

2.2 XPS depth profiling. XPS depth profiling is done by $\mathrm{Ar}^{+}$ion sputtering, combining XPS analysis with cyclic etching to obtain depth information. Record the energy spectrum of the sample surface before etching, and then record a set of energy spectra after an etching. Etching and energy spectrum collection are repeated in this way until the desired depth is analyzed. Under these conditions, the sputtering rate of $\mathrm{Au} @ \mathrm{AuIr}_{2}$ is $0.5 \AA / \mathrm{s}$. The etching time is $10 \mathrm{~s}, 20$ s, $40 \mathrm{~s}$ and $60 \mathrm{~s}$, respectively. All peak energies are referenced to the adventitious $\mathrm{C} 1 \mathrm{~s}, \mathrm{C}-\mathrm{C}$ peak at $284.8 \mathrm{eV}$ for calibration purposes. 
2.3 XAS Measurements. The X-ray absorption fine structure spectra measurements ( $\mathrm{Au} L_{3}$-edge and $\operatorname{Ir} L_{3}$-edge) were investigated by the BL14W1 in Shanghai Synchrotron Radiation Facility (SSRF). The electron beam energy was $3.5 \mathrm{GeV}$ and the stored current was $230 \mathrm{~mA}$ (top-up). The X-ray energy was selected by a Si (111) double crystal monochromator and calibrated with metals foil. All samples were pelletized into disks of $5 \mathrm{~mm}$ diameter with $1 \mathrm{~mm}$ thickness and collected in transmission mode. The obtained XAFS data was performed utilizing the Athena module in the IFEFFIT package, in accordance with standard procedures. After pretreating, the pre-edge line and post-edge line as background was deducted from the overall XAFS spectra and then normalized to obtain the EXAFS spectra. To investigate the coordination conditions of Ir center, the spectrum in k-space was transformed from the spectrum in E-space then further deconvolved by the wavelet transform (WT) method, which provides a radial distance resolution and the resolution in the $\mathrm{K}$ space. The EXAFS contributions were separate from different coordination shells by Fourier transforming the $\chi(k)$ function to real (R) space using a hanning windows $\left(d k=1.0 \AA^{-1}\right)$. Subsequently, the ARTEMIS module in the IFEFFIT package was used to the least-squares curve parameter fitting to obtain the quantitative structural parameters around $\mathrm{Au}$ and $\mathrm{Ir}$ atoms. The $\mathrm{k}$ range of $\mathrm{Au} L_{3}$-edge EXAFS fitting is 3.0-11.1 $\AA^{-1}$, whereas that of Ir $L_{3}$-edge EXAFS fitting is $3.0-10.5 \AA^{-1}$. During the curve-fitting of Au $L_{3}$-edge and $\operatorname{Ir}$ $L_{3}$-edge, the overall amplitude reduction factor $\mathrm{SO}_{2}$ was fixed to the best-fit value determined from fitting the data of metal $\mathrm{Au}$ foil and Ir powder. For the Au@AuIr 2 , the structural parameters, including the coordination number $\mathrm{N}$, interatomic distance $\mathrm{R}$, the Debye-Waller factor $\sigma^{2}$ and the edge-energy shift $\mathrm{E}_{0}$ were allowed to vary during the fitting process. The bond distances were adjusted based on initial inputs from standard crystal structure information files of $\mathrm{Ir}, \mathrm{Au}$ and $\mathrm{IrO}_{2}$ for the fits of $\mathrm{Au}-\mathrm{Au}, \mathrm{Au}-\mathrm{Ir}, \mathrm{Ir}-\mathrm{Au}$, Ir-Ir and Ir-O bond, respectively.

2.4 Electrochemical Measurements. HER and OER electrochemical measurements were measured by an IM6 electrochemical workstation (Zahner, Germany) equipped with a rotating disk electrode (RDE) (PINE 710, USA) in a three-electrode electrolytic cell. In this system, a Platinum net electrode (for OER, $1 \mathrm{~cm}^{2}$ ), carbon rod electrode (for HER) and $\mathrm{Ag} / \mathrm{AgCl}$ (Gaoss Union, saturated $\mathrm{KCl}$ ) were used as counter electrode and reference electrode, respectively. The working electrode (WE) was a glassy carbon electrode (GCE) $\left(5 \mathrm{~mm}\right.$ diameter, $\left.0.196 \mathrm{~cm}^{2}\right)$ 
equipped with as-synthesized catalysts. To prepare the working electrode, $4 \mathrm{mg}$ of the as-synthesized Au@AuIr 2 catalyst was dispersed in $1940 \mu l$ isopropanol and $60 \mu l$ Nafion solution ( $5 \mathrm{wt} \%$ nafion, Sigma-Aldrich) by ultrasonic treating for about $2 \mathrm{~h} .10 \mu \mathrm{l}$ of the catalyst ink was pipetted onto the polished GCE surface, leading to the metal loading of $60 \mu \mathrm{g} / \mathrm{cm}^{2}$ (i.e., $20 \mu g_{I r} / \mathrm{cm}^{2}$ ), and then the as-prepared WE was dried at room temperature. Similar to the $\mathrm{Au} @ \mathrm{AuIr}_{2}$ catalyst, $4 \mathrm{mg}$ of the commercial Ir/C or Pt/C was dispersed in $1940 \mu l$ isopropanol and $60 \mu l$ Nafion solution under ultrasonication for $2 \mathrm{~h} .10 \mu l$ of the suspension was deposited on a clean glassy carbon RDE and dried at room temperature. The loading amount of Ir/Pt for the commercial electrocatalyst on RDE was also $20 \mu \mathrm{g} / \mathrm{cm}^{2}$. Before electrocatalysis measurements, the cyclic voltammetry (CV) was used to remove covering surfactants from catalysts in $\mathrm{N}_{2}$-saturated $0.5 \mathrm{M} \mathrm{H}_{2} \mathrm{SO}_{4}$ solution at a sweep rate of $100 \mathrm{mV} / \mathrm{s}$ from 0 to $0.4 \mathrm{~V}$ (versus $\mathrm{Ag} / \mathrm{AgCl}$ ). The OER electrocatalytic activity was performed in $\mathrm{O}_{2}$-saturated $0.5 \mathrm{M} \mathrm{H}_{2} \mathrm{SO}_{4}$ solution using linear sweep voltammetry from $1.0 \mathrm{~V}$ to $1.4 \mathrm{~V}$ (versus $\mathrm{Ag} / \mathrm{AgCl}$ ) with the scan rate of $10 \mathrm{mV} / \mathrm{s}$. The HER electrocatalytic activity was tested in $\mathrm{N}_{2}$-saturated $0.5 \mathrm{M} \mathrm{H}_{2} \mathrm{SO}_{4}$ solution using linear sweep voltammetry from $-0.1 \mathrm{~V}$ to $-0.3 \mathrm{~V}$ (versus $\mathrm{Ag} / \mathrm{AgCl}$ ) with the scan rate of $10 \mathrm{mV} / \mathrm{s}$. All HER and OER measurements were conducted under rotating at $1600 \mathrm{rpm}$ to remove the produced bubbles at room temperature, with $90 \%$ iR-drop correction. The chronopotentiometry test of OER was set a constant current density of $10 \mathrm{~mA} / \mathrm{cm}^{2}$ for $30 \mathrm{~h}$ using the rotating disk electrode under a constant rotation rate of $1600 \mathrm{rpm}$ in $\mathrm{O}_{2}$-saturated $0.5 \mathrm{M}$ $\mathrm{H}_{2} \mathrm{SO}_{4}$, and the operating potentials were recorded as a function of time. The overall water splitting was investigated in a two-electrode system, dropping catalyst on carbon fiber papers as both anode and cathode (loading amount of $20 \mu g_{\mathrm{Ir}} / \mathrm{cm}^{2}$ ).

2.5 Turnover Frequency (TOF, $\left.\mathbf{s}^{-1}\right)$. The TOF for $\mathrm{O}_{2}$ was calculated as follow:

$$
T O F=\frac{I_{\text {product }} / N F}{m_{c a t} \times \omega / M_{I r}}
$$

$I_{\text {product }}:$ partial current for certain product, $\mathrm{O}_{2}$;

$N$ : the number of electron transferred for product formation, which is 4 for $\mathrm{O}_{2}$; F: Faradaic constant, $96485 \mathrm{C} \mathrm{mol}^{-1}$; 
$\mathrm{m}_{\text {cat }}:$ catalyst mass in the electrode, $\mathrm{g}$;

$\omega$ : Ir loading in the catalyst;

$M_{I r}$ : atomic mass of Ir, $192.22 \mathrm{~g} \mathrm{~mol}^{-1}$.

2.6 Electrochemically active surface area (ECSA). The initial specific electrochemically active surface areas (ECSAs) of $\mathrm{Pt} / \mathrm{C}, \mathrm{Ir} / \mathrm{C}$, and $\mathrm{Au} @ \mathrm{AuIr}_{2}$ catalysts were measured by calculating the underpotentially deposited $\left(H_{\text {upd }}\right)$ area from the cyclic voltammetry curves. ${ }^{1}$ And these were evaluated from the third cycle of a total of five CV scans performed between +0.05 and $+1.05 \mathrm{~V}$ vs RHE for Pt/C and +0.05 and $+0.55 \mathrm{~V}$ vs RHE for Ir-based catalysts, with a $50 \mathrm{mV} / \mathrm{s}$ scan rate in $\mathrm{N}_{2}$-saturated $0.5 \mathrm{M} \mathrm{H}_{2} \mathrm{SO}_{4}$ solution. The ECSA of each electrocatalyst was calculated on the basis of charges associated with the desorption of hydrogen in the region of $0.06-0.4 \mathrm{~V}$ after double-layer correction with a reference value of $210 \mu \mathrm{C} / \mathrm{cm}^{2}$. The ECSA of Au was estimated from the reduction peak charge of Au oxides $\left(390 \mu \mathrm{C} / \mathrm{cm}^{2}\right)$, measured from $\mathrm{CV}$ between 0.2 and $1.7 \mathrm{~V}$ at a sweep rate of $50 \mathrm{mV} / \mathrm{s}$ in $\mathrm{N}_{2}$-saturated $0.5 \mathrm{M} \mathrm{H}_{2} \mathrm{SO}_{4}$ solution.

2.7 Calibrate to reversible hydrogen electrode (RHE). The calibration was conducted in $\mathrm{H}_{2}$-saturated 0.5 $\mathrm{M} \mathrm{H}_{2} \mathrm{SO}_{4}$ electrolyte with a three-electrode system, i.e., $\mathrm{Ag} / \mathrm{AgCl}$ (saturated $\mathrm{KCl}$ ), Pt wire and carbon rod as the reference electrode, working electrode and counter electrode, respectively. Cyclic voltammograms were measured at a scan rate of $1 \mathrm{mV} / \mathrm{s}$ from -0.1 to $-0.35 \mathrm{~V}$ (versus $\mathrm{Ag} / \mathrm{AgCl}$ ). The thermodynamic potential for the hydrogen electrode reactions was the average of the two potentials that the current reached zero $(198 \mathrm{mV})$. All the potentials reported in this article were calibrated and converted to the RHE using the equation:

$$
E_{\mathrm{RHE}}=E_{\mathrm{Ag} / \mathrm{AgCl}}+0.198 \mathrm{~V}+0.0591 \times \mathrm{pH} .
$$

2.8 Electrochemical impedance spectroscopy (EIS). The electrochemical impedance spectroscopy (EIS) was measured in the range of $100 \mathrm{k}-10 \mathrm{~m} \mathrm{~Hz}$ with an amplitude of $5 \mathrm{mV}$. For OER, the external voltage was $1.51 \mathrm{~V}$ (at the overpotential of $280 \mathrm{mV}$ ) vs. RHE. ZSimpWin was used for equivalent circuit fitting of EIS data. The fitting data is shown in Table S5. 


\section{Calculation details}

3.1 DFT Calculations. The Ir surface was modeled by a periodic slab consisting of five layers in the (111) direction, with a $3 * 3$ supercell in the two lateral directions. Au-Ir core-shell system was constructed based on the $\operatorname{Ir}(111)$ surface model, in which the component gradually changes from the pure $\mathrm{Au}$ on the bottom layer, to the pure Ir on the top layer. The partially oxidized species were constructed by using eight oxygen atoms precovered on the $f c c$ site of top layer in a unit cell. During structural optimization, the bottom two layers were frozen and the top three layers and adsorbed species were fully relaxed.

All the electronic structure calculations were performed using the plane-wave periodic density functional theory as implemented in the Vienna $a b$ initio simulation package (VASP). ${ }^{2-4}$ The projector augmented-wave (PAW) method developed by Blöchl ${ }^{5}$ to describe the electron-ion interactions using plane wave basis sets was employed. The generalized gradient approximation (GGA) with the Perdew-Burke-Ernzerh (PBE) exchange-correlation functional was used. ${ }^{6}$ The kinetic energy cutoff was set to $450 \mathrm{eV}$. The convergence criteria for the energy calculations were set to a self-consistent field $(\mathrm{SCF})$ tolerance of $1.0 \times 10^{-5} \mathrm{eV}$. All internal structure parameters were relaxed until the maximum Hellmann-Feynman force on each ion were less than $0.02 \mathrm{eV} / \AA$. Integration over the Brillouin zone was achieved with k-points mesh of $5 * 5 * 1$ according to the Monkhorst-Pak scheme ${ }^{7}$ together with a smearing method in Methfessel-Paxton scheme (order 1) broadening of $0.1 \mathrm{eV}$. The numerical calculation of the second derivatives of the harmonic potential energy surface provided the vibrational frequencies and corresponding normal modes. A geometrical displacement of $0.01 \AA$ was used for all vibrational calculations. The final free energy changes for electrochemical processes were calculated in combination with the computational Standard Hydrogen Electrode (SHE) model.

Previous work has demonstrated that the oxygen coupling $\left({ }^{*} \mathrm{O}+{ }^{*} \mathrm{O}\right)$ reaction is less favorable than the formation of $* \mathrm{OOH}$ intermediate. ${ }^{8}$ Thus, we considered a four-step mechanism under acidic condition, which involves the following reaction steps. ${ }^{9}$

$*+\mathrm{H}_{2} \mathrm{O}(\mathrm{l}) \rightarrow{ }^{*} \mathrm{OH}+\mathrm{H}^{+}+\mathrm{e}^{-}$

$* \mathrm{OH} \rightarrow * \mathrm{O}+\mathrm{H}^{+}+\mathrm{e}^{-}$ 
$* \mathrm{O}+\mathrm{H}_{2} \mathrm{O}(\mathrm{l}) \rightarrow * \mathrm{OOH}+\mathrm{H}^{+}+\mathrm{e}^{-}$

$* \mathrm{OOH} \rightarrow *+\mathrm{O}_{2}(\mathrm{~g})+\mathrm{H}^{+}+\mathrm{e}^{-}$

The symbol (*) represents the active site of catalysts.

3.2 Modeling of Ir. The Ir surface was modeled by a periodic slab consisting of five layers in the (111) direction, with a $3 * 3$ supercell in the two lateral directions. In all calculations, the bottom two layers were frozen and the top three layers and adsorbed species were fully relaxed.

3.3 Modeling of Au@AuIr 2 . Au-Ir core-shell system was constructed based on the $\operatorname{Ir}(111)$ surface model, in which the component gradually changes from the pure Au on the bottom layer, to the pure Ir on the top layer. As the HAADF-STEM shows that the Au@AuIr 2 is core-shell structure with the shell of four atom layers. We built the Au@AuIr 2 model consisting of five layers in the (111) direction, on the top four layers with the ratio of $\mathrm{Au}: \mathrm{Ir}=1: 2$, close to the experimental value of 1:2.06 (Figure S4).

3.4 Modeling of $\operatorname{IrO}_{\mathrm{x}}$. The partially oxidized species $\mathrm{IrO}_{\mathrm{x}}$ was constructed by using eight oxygen atoms precovered on the fcc site of top layer in the Ir unit cell.

3.5 Modeling of $\mathbf{A u} @ \mathrm{AuIr}_{2} \mathrm{O}_{\mathbf{x}}$. The partially oxidized species $\mathrm{Au} @ \mathrm{AuIr}_{2} \mathrm{O}_{\mathrm{x}}$ was constructed by using eight oxygen atoms precovered on the fcc site of top layer in the $\mathrm{Au} @ \mathrm{AuIr}_{2} \mathrm{O}_{\mathrm{x}}$ unit cell.

3.6 Free energy diagram. The free energies of reactant, product, and reaction intermediates as shown in Figure 4 are calculated using Equations 1-4: 8

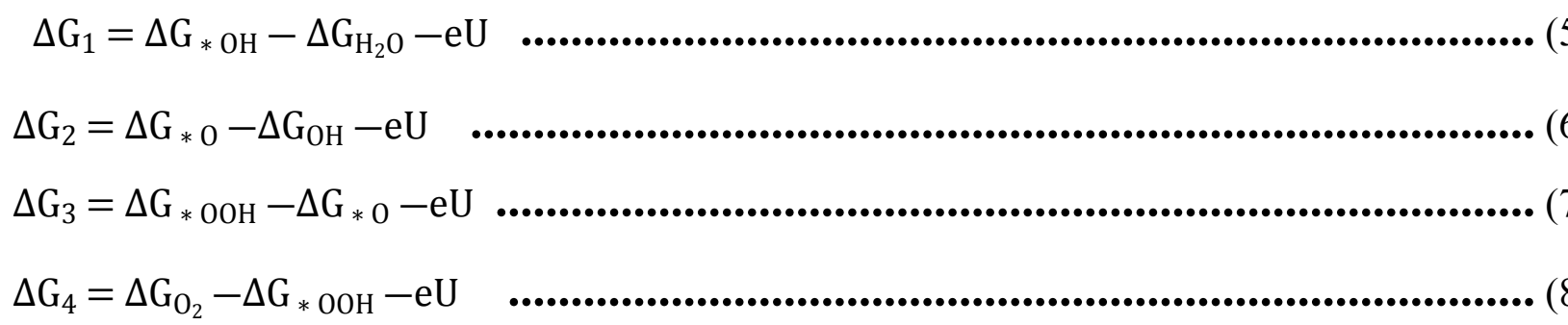

Where $\Delta \mathrm{G}_{1}-\Delta \mathrm{G}_{4}$ represent the reaction free energies of four elementary steps for OER. The theoretical overpotential $\eta$ was calculated as Equation (9):

$\eta=\operatorname{Max}\left\{\Delta \mathrm{G}_{1}, \Delta \mathrm{G}_{2}, \Delta \mathrm{G}_{3}, \Delta \mathrm{G}_{4}\right\} / \mathrm{e}-1.23 \mathrm{~V}$

The $\mathrm{O}$ and $\mathrm{OH}$ binding energies $E_{b}$ were calculated as Equation (10):

$E_{b}=E_{a d s^{*}}-E_{*}-E_{a d s}$

Where $E_{a d s} *$ is the energy of surface with the target adsorbate, $E_{*}$ is the energy of the surface 
without the target adsorbate, and $E_{a d s}$ is the energy of the adsorbate in vacuum (calculated with spin-polarization). 


\section{Supplementary Figures and Tables}
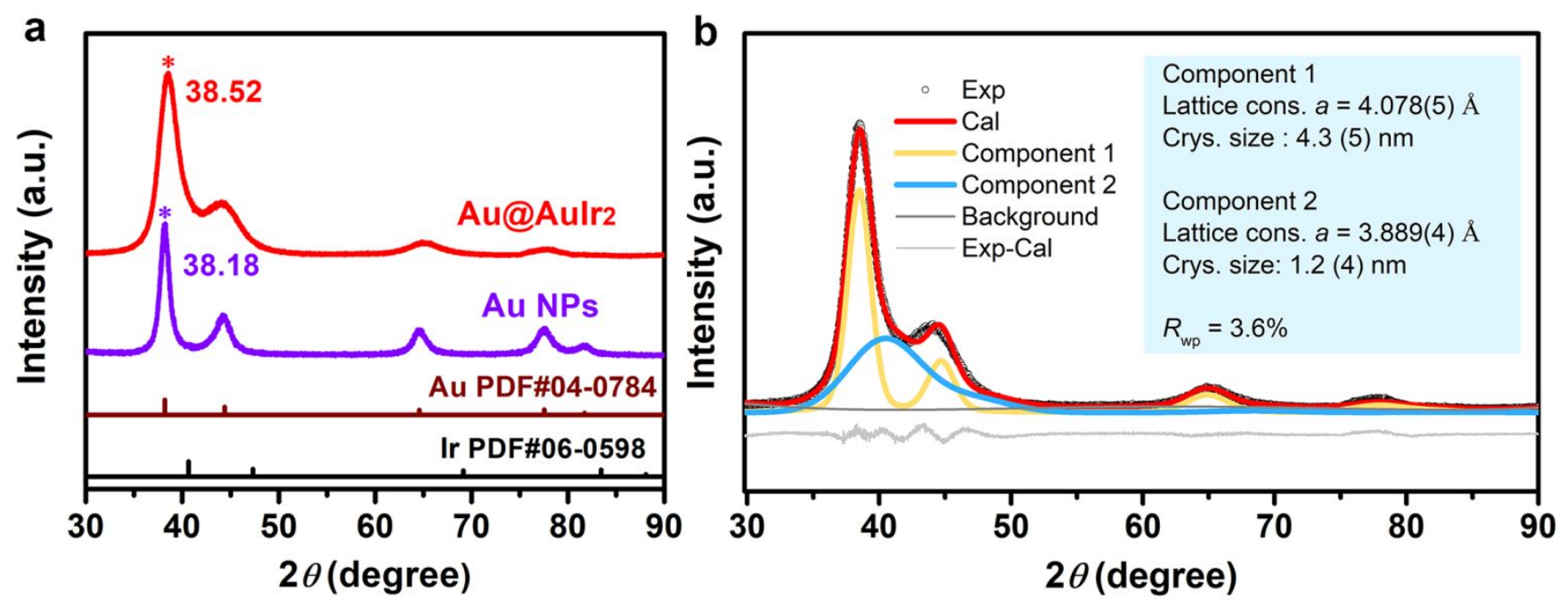

Figure S1. (a) PXRD patterns of Au@AuIr ${ }_{2}$ and Au NPs. The standard XRD patterns of bulk gold (PDF\# 04-0784) and iridium

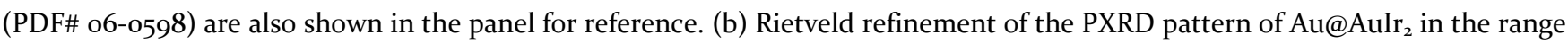
of $2 \theta=30-90^{\circ}$. The raw data, fitting profile, differences, component 1 , component 2 and background are shown as black open circles and red, light gray, yellow, blue, and gray solid lines, respectively.

The peak location of the obtained Au NPs is consistent with that of bulk Au (PDF\# 04-0784). The lattice of component 1 is constant with the Au bulk $(a=4.078 \AA$ ). Based on Vegard's law, component 2 gives an atomic ratio of $\mathrm{Au}$ : $\mathrm{Ir}=0.21$ : 0.79, which is different with that given by EDS (ca. 0.33: 0.67). This difference mainly comes from the relative less crystalline surfaces which are not well resolved by the PXRD. However, the Rietveld refinement does confirm that the surface is AuIr alloy. 

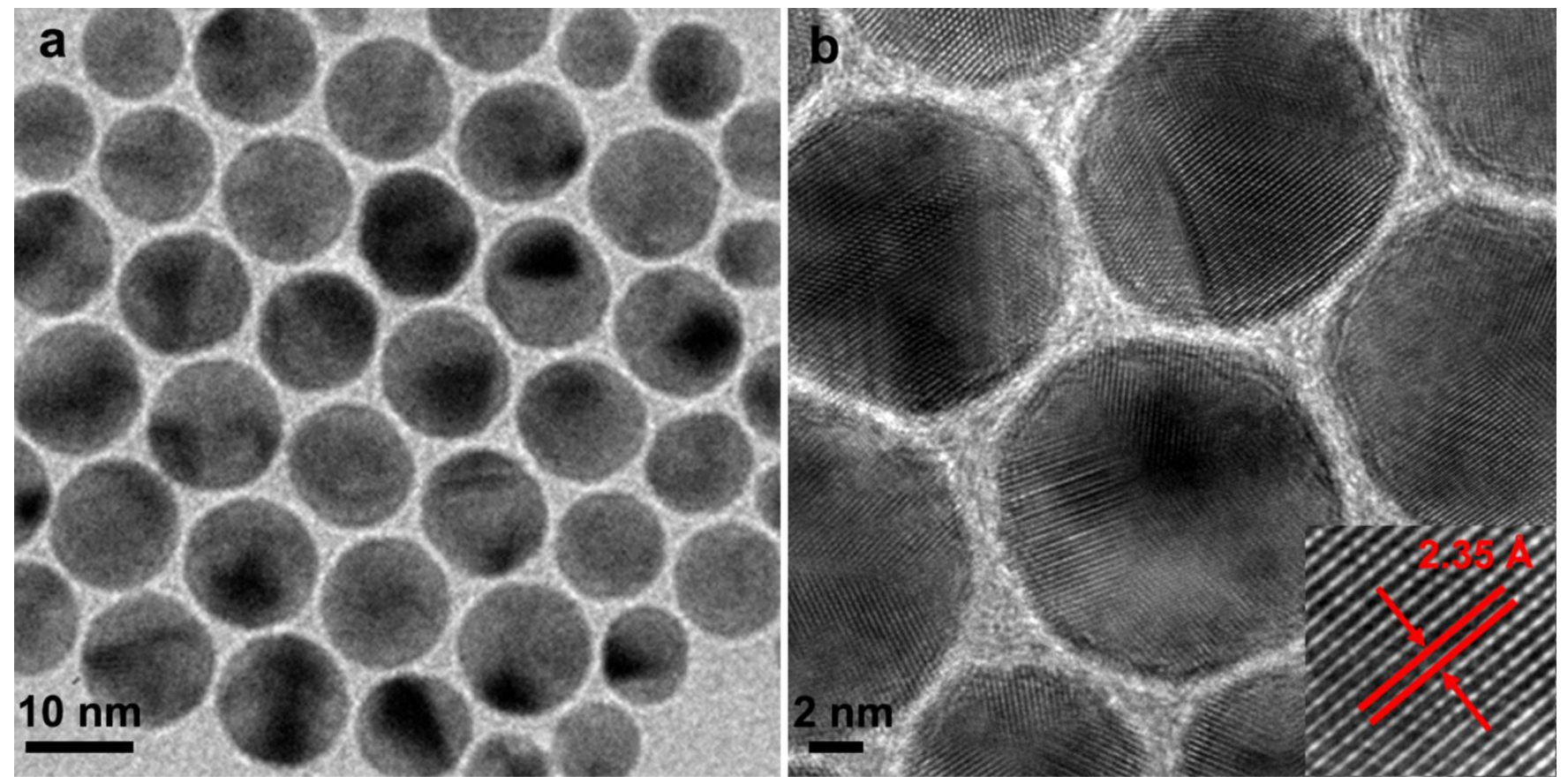

Figure S2. (a) TEM and (b) HRTEM images of home-made Au NPs. 

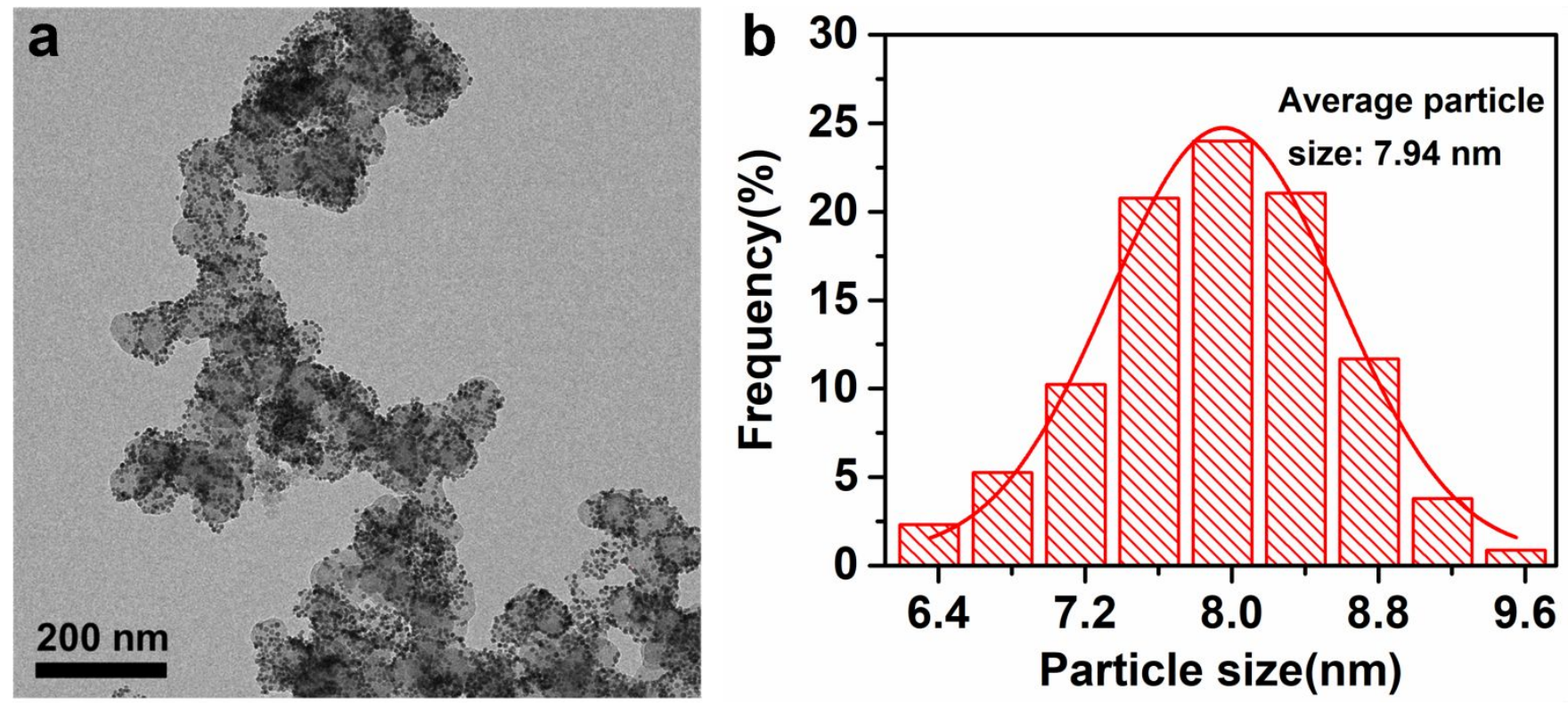

Figure S3. (a) TEM image and (b) size distribution of Au@AuIr 2 . 


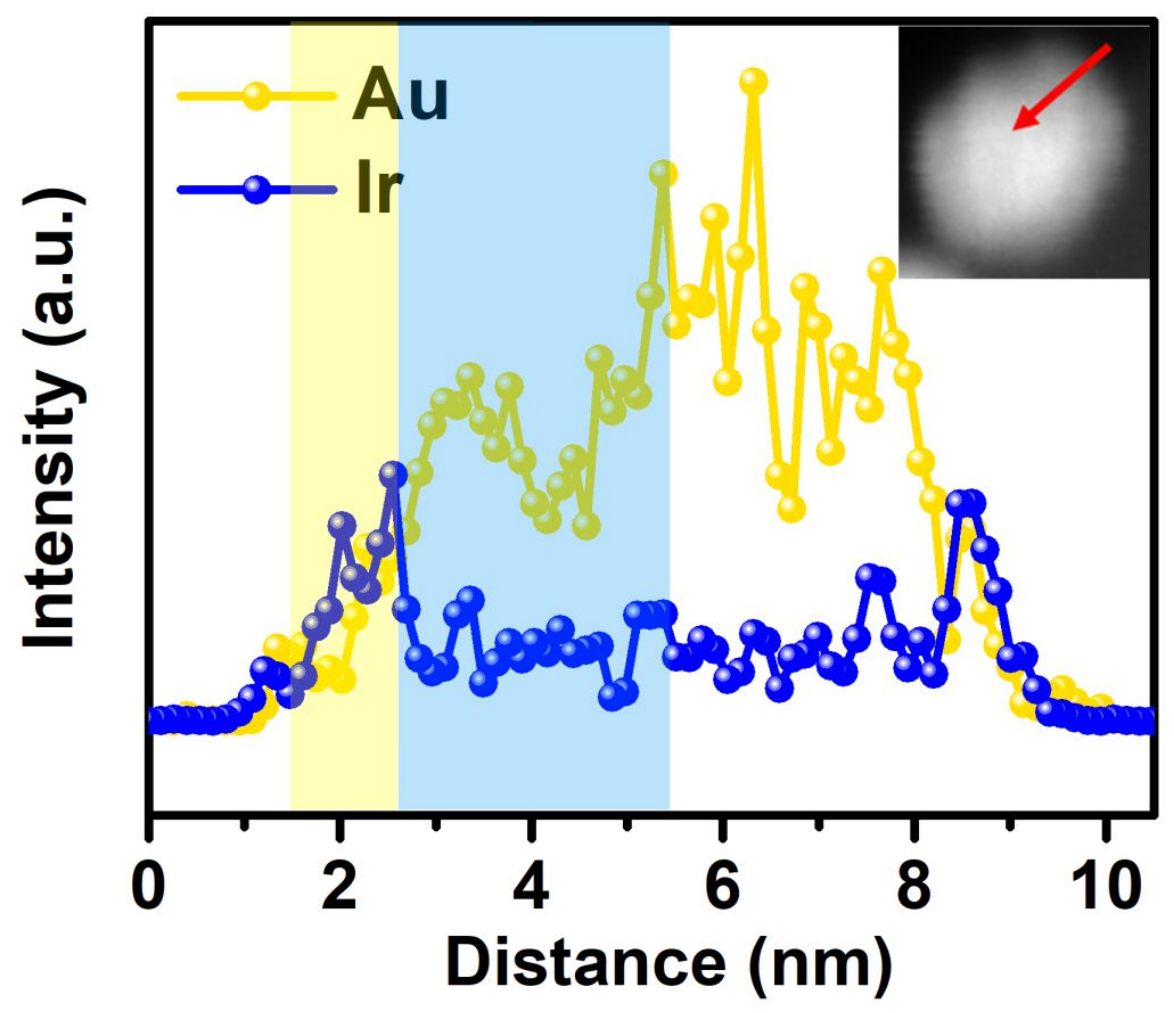

Figure S4. EDX line scan analysis of Au@AuIr $r_{2}$ along the red arrow marked in the inset. 


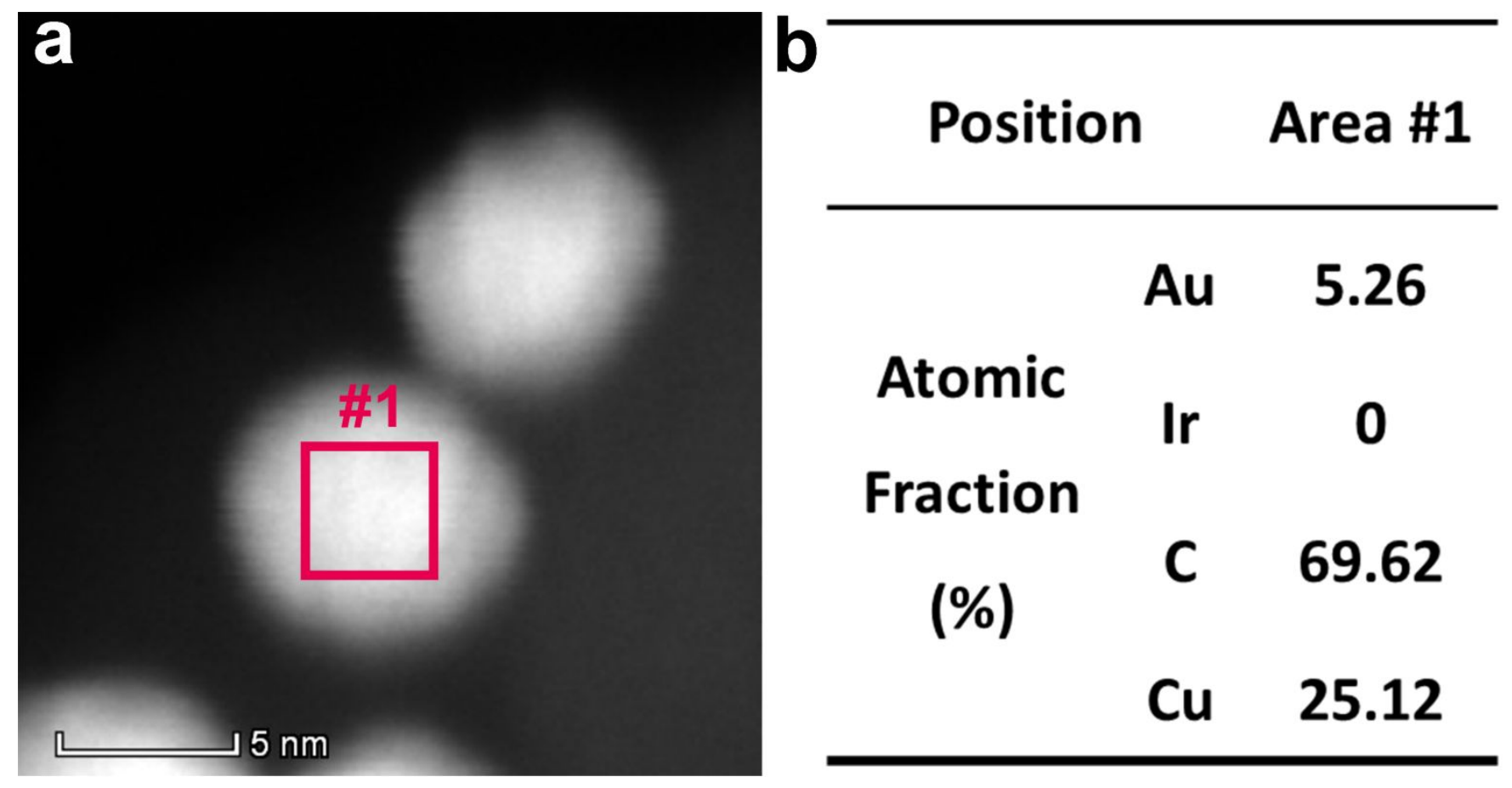

Figure S5. (a) HAADF-STEM image of Au@AuIr ${ }_{2}$, (b) The atomic ratios confirmed by EDS analysis. 


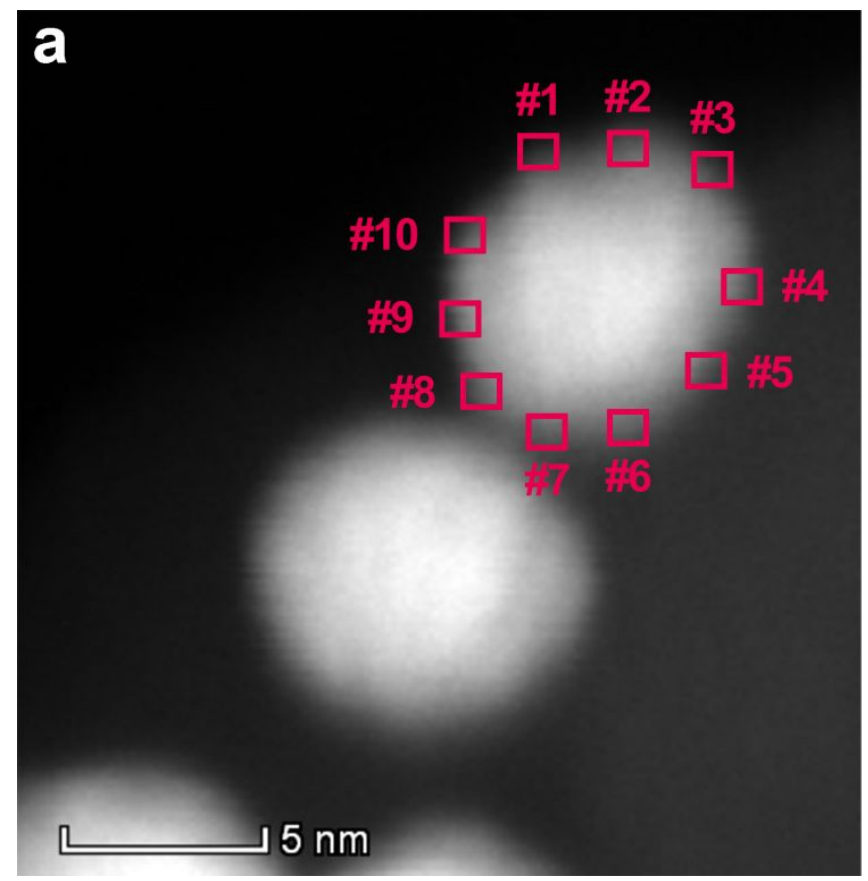

\begin{tabular}{ccc}
\hline b & \multirow{2}{*}{ Position } & \multicolumn{2}{c}{ Atomic } & Fraction (\%) \\
& Au & 72.32 \\
\hline Area \#1 & 27.68 & 68.54 \\
Area \#2 & 31.46 & 64.75 \\
Area \#3 & 35.25 & 69.23 \\
Area \#4 & 30.77 & 67.70 \\
Area \#5 & 32.30 & 63.59 \\
Area \#6 & 36.41 & 66.60 \\
Area \#7 & 33.40 & 69.02 \\
Area \#8 & 30.98 & 64.39 \\
Area \#9 & 35.61 & 66.78 \\
Area \#10 & 33.22 & 67.29 \\
average & 32.71 &
\end{tabular}

Figure S6. (a) HAADF-STEM image of Au@AuIr 2 , (b) The atomic ratios on different positions, which were confirmed by EDS analysis. 


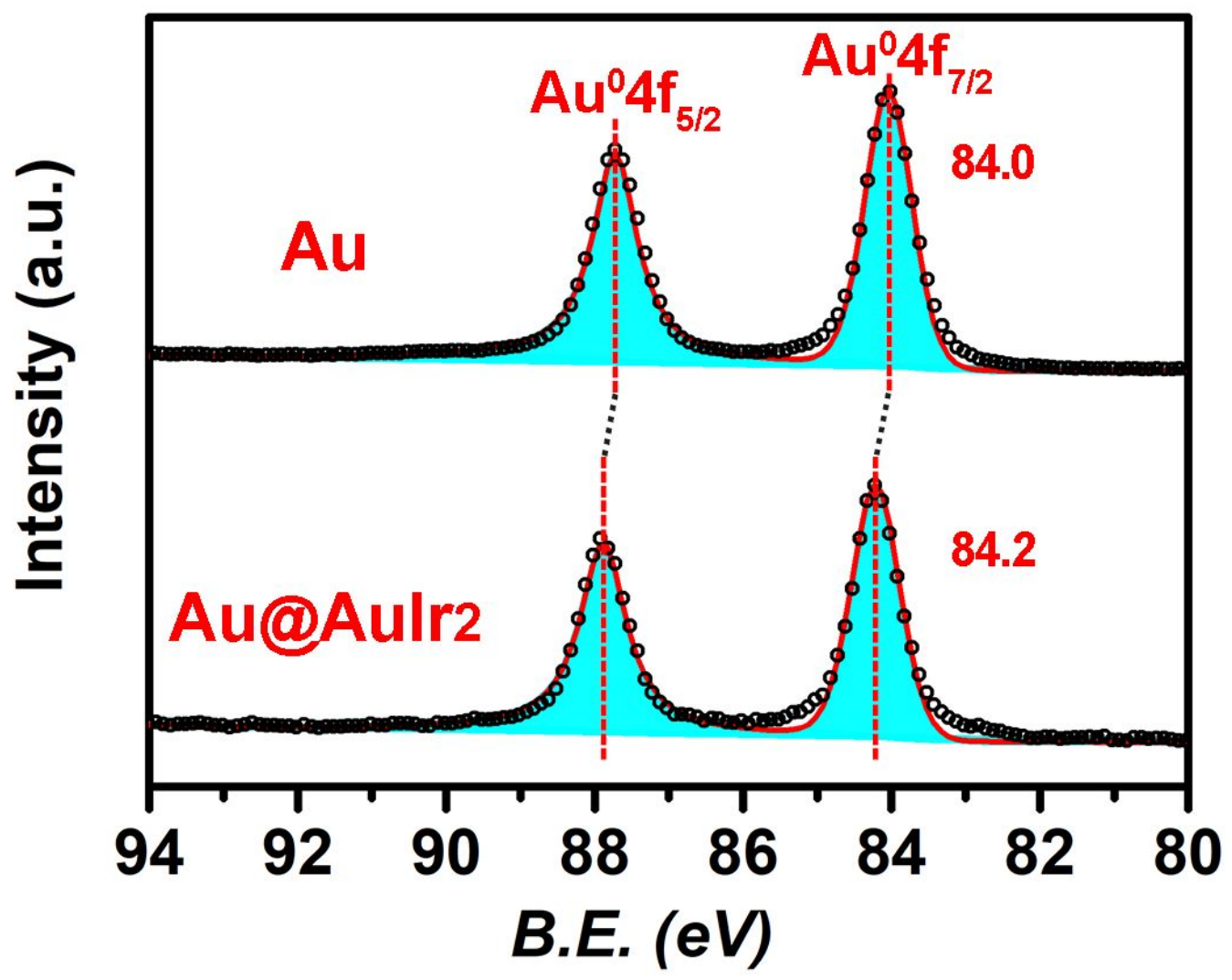

Figure $S_{7}$. XPS spectra for the Au 4 f regions of Au@AuIr 2 and Au NPs: XPS raw data (black open cycles) and fitting curves (red line). 


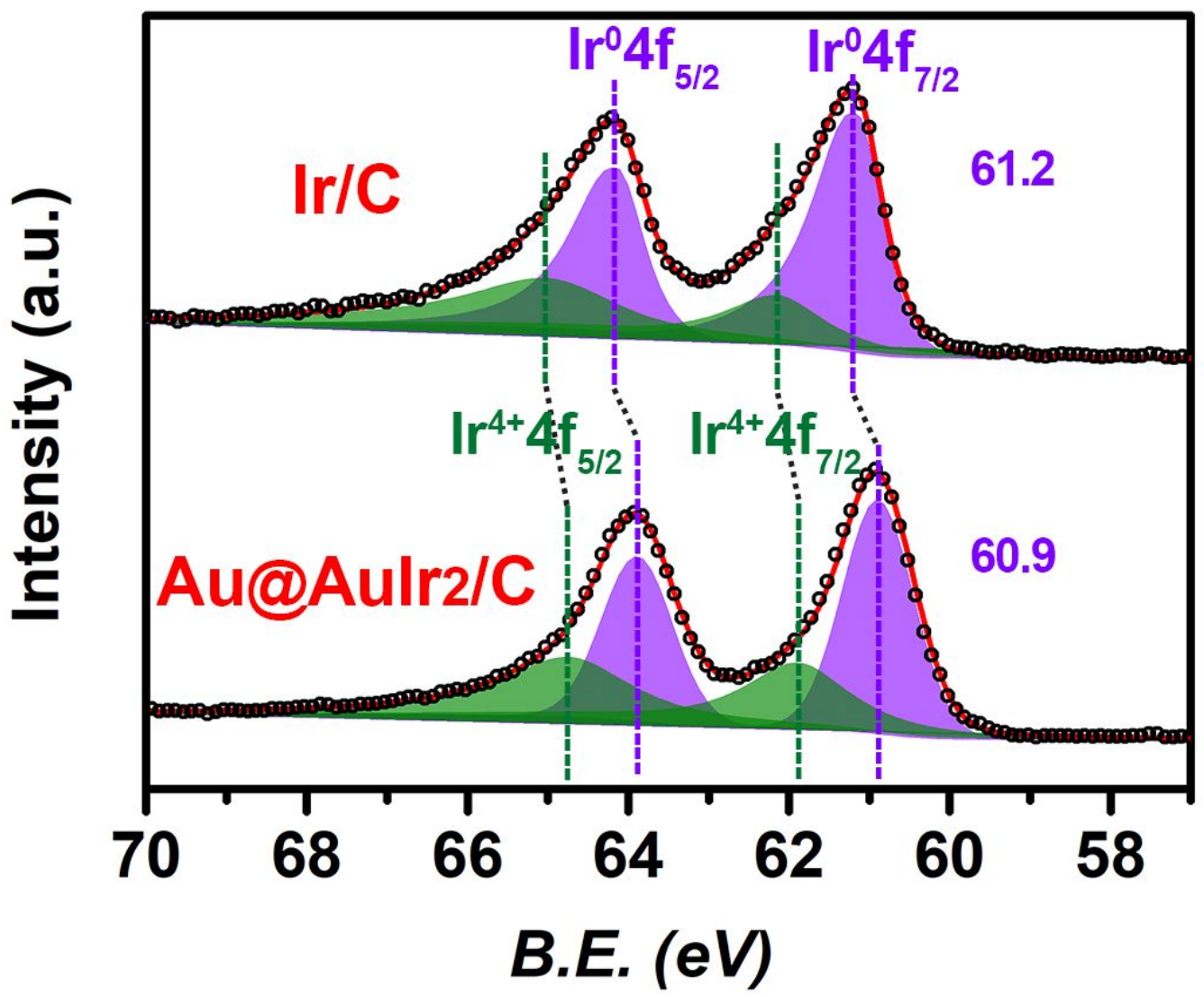

Figure S8. XPS spectra for the Ir 4 f regions of $A u @ A u r_{2} / C$ and commercial Ir/C: XPS raw data (black open cycles) and fitting curves (red line). 


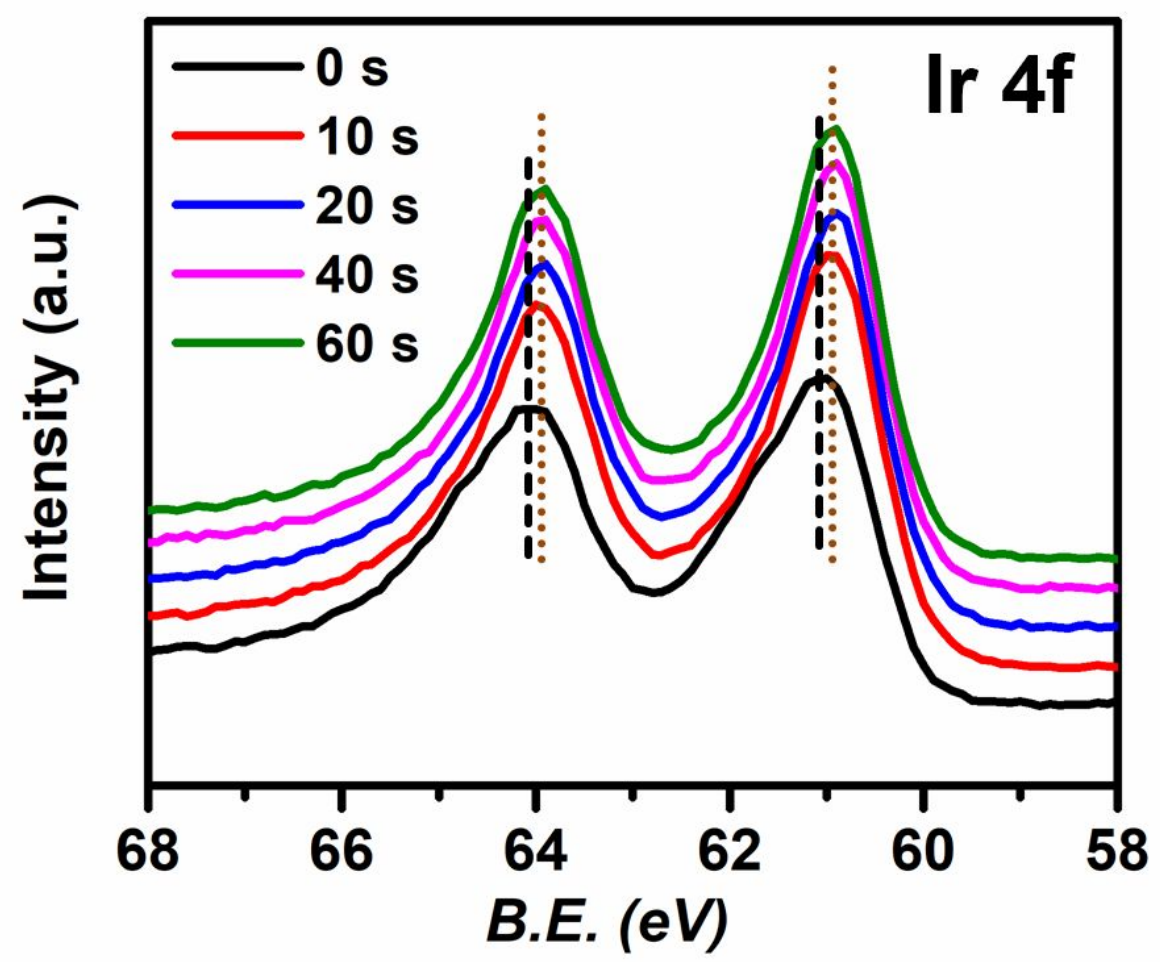

Figure S9. Ir 4f XPS spectra of Au@AuIr $\mathrm{s}$ (blue line), $40 \mathrm{~s}$ (magenta line) and 6o s (olive line) sputtering. 


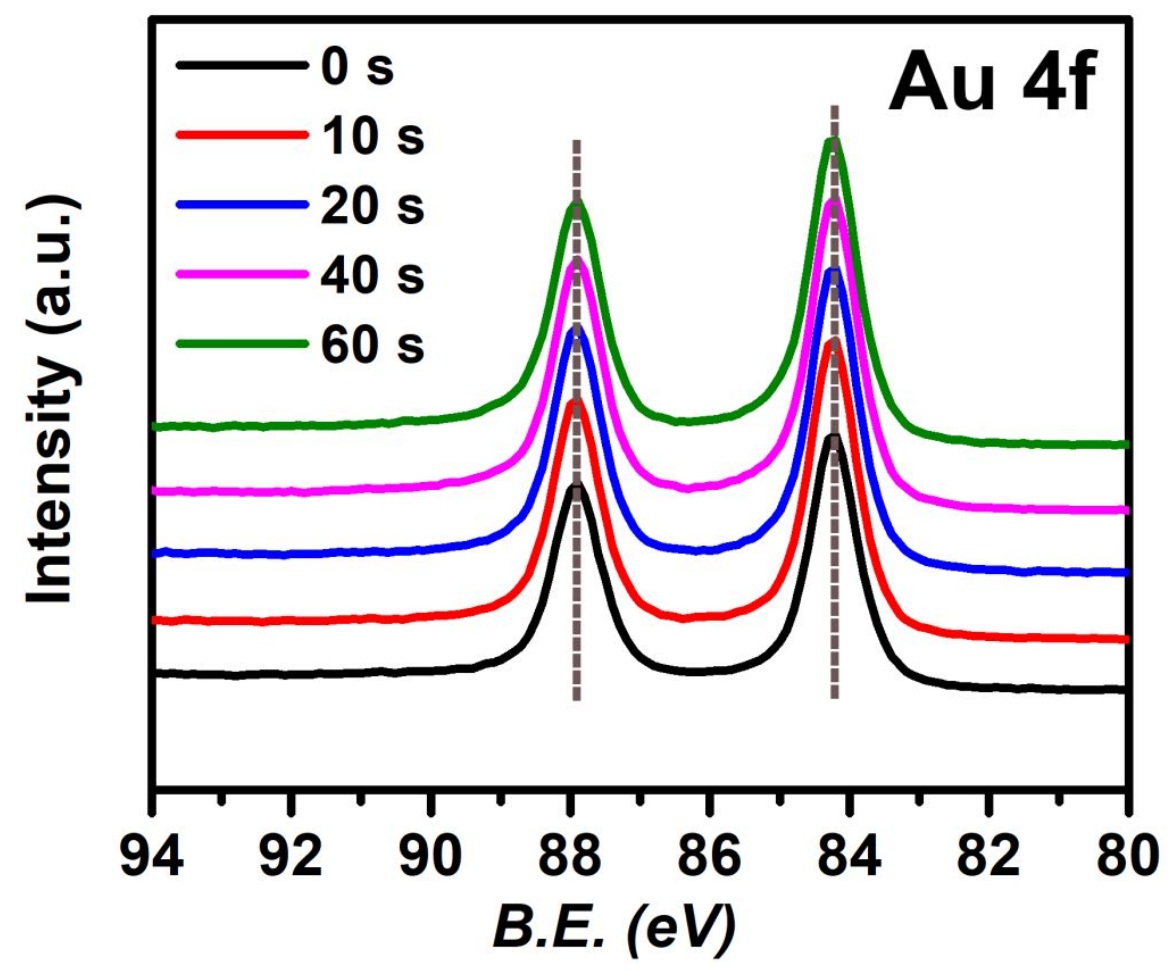

Figure S1o. Au $4 \mathrm{f}$ XPS spectra of Au@AuIr $r_{2}$ the different curves show the Au@AuIr ${ }_{2}$ before (black line) and after $10 \mathrm{~s}$ (red line), $20 \mathrm{~s}$ (blue line), $40 \mathrm{~s}$ (magenta line) and 6o s (olive line) sputtering. 


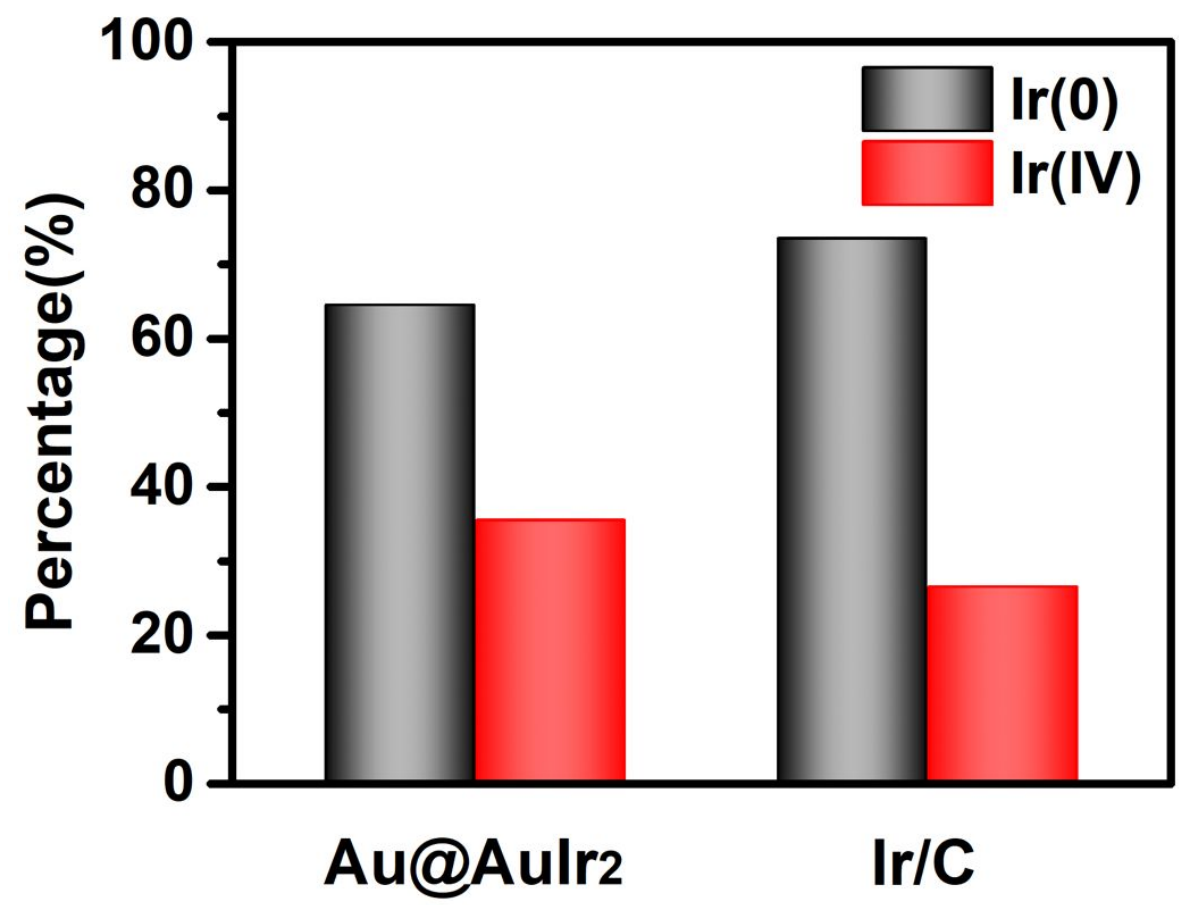

Figure S11. IrO $\mathrm{IO}_{\mathrm{X}}$ percentage (estimated by XPS) of Au@AuIr ${ }_{2}$ and commercial Ir/C. 


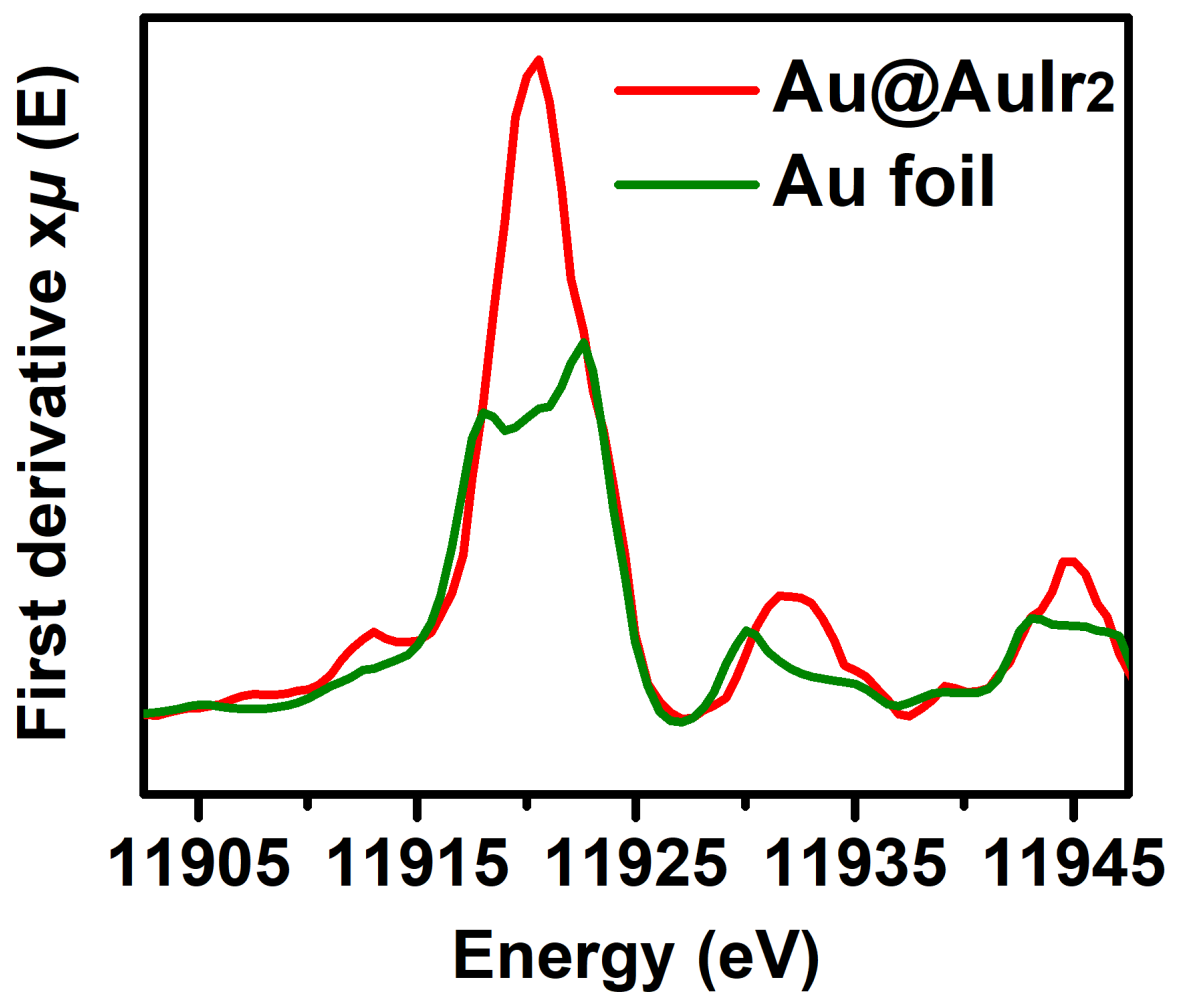

Figure S12. Normalized first derivative of the $\mathrm{Au} L_{3}$-edge XANES spectra. 

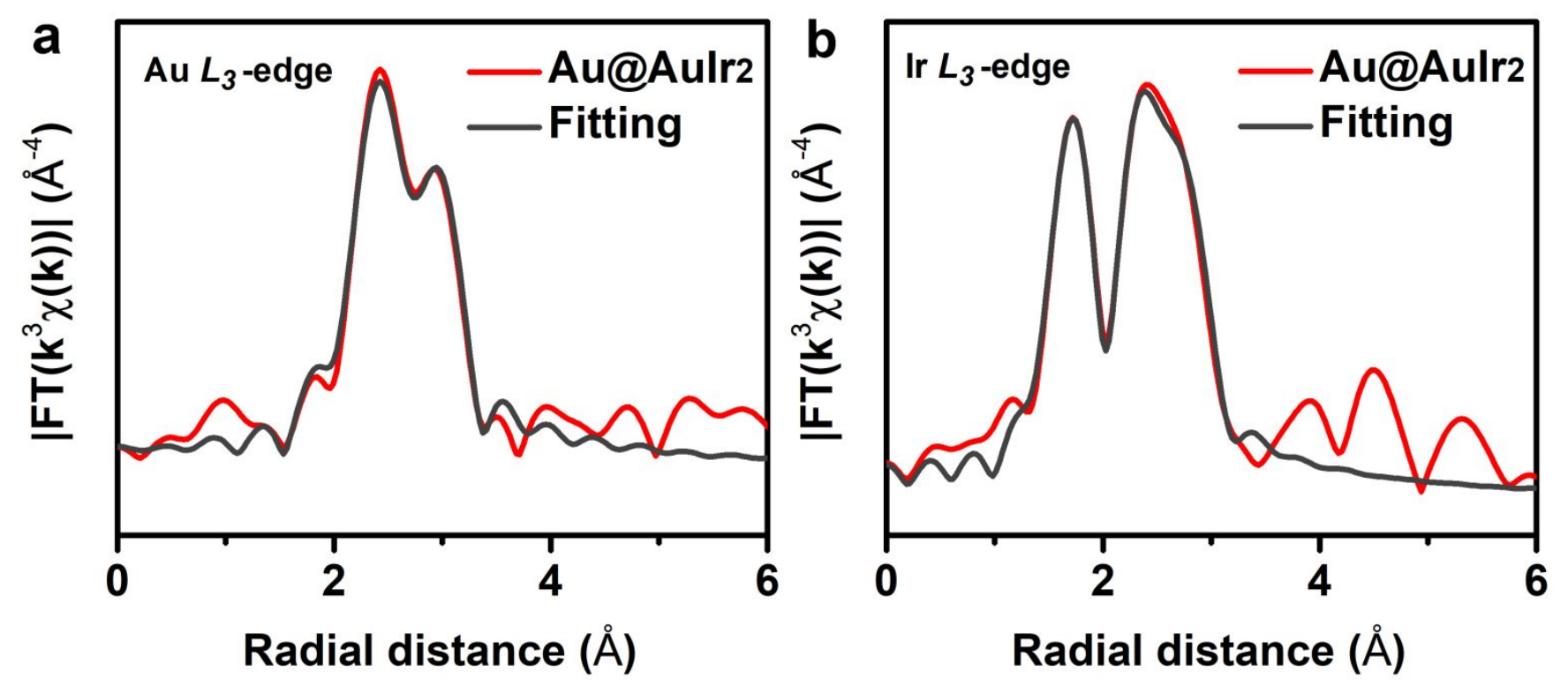

Figure S13. The fitting Au $L_{3}$-edge EXAFS spectrum (a) and Ir $L_{3}$-edge EXAFS spectrum (b) of Au@AuIr ${ }_{2}$. 

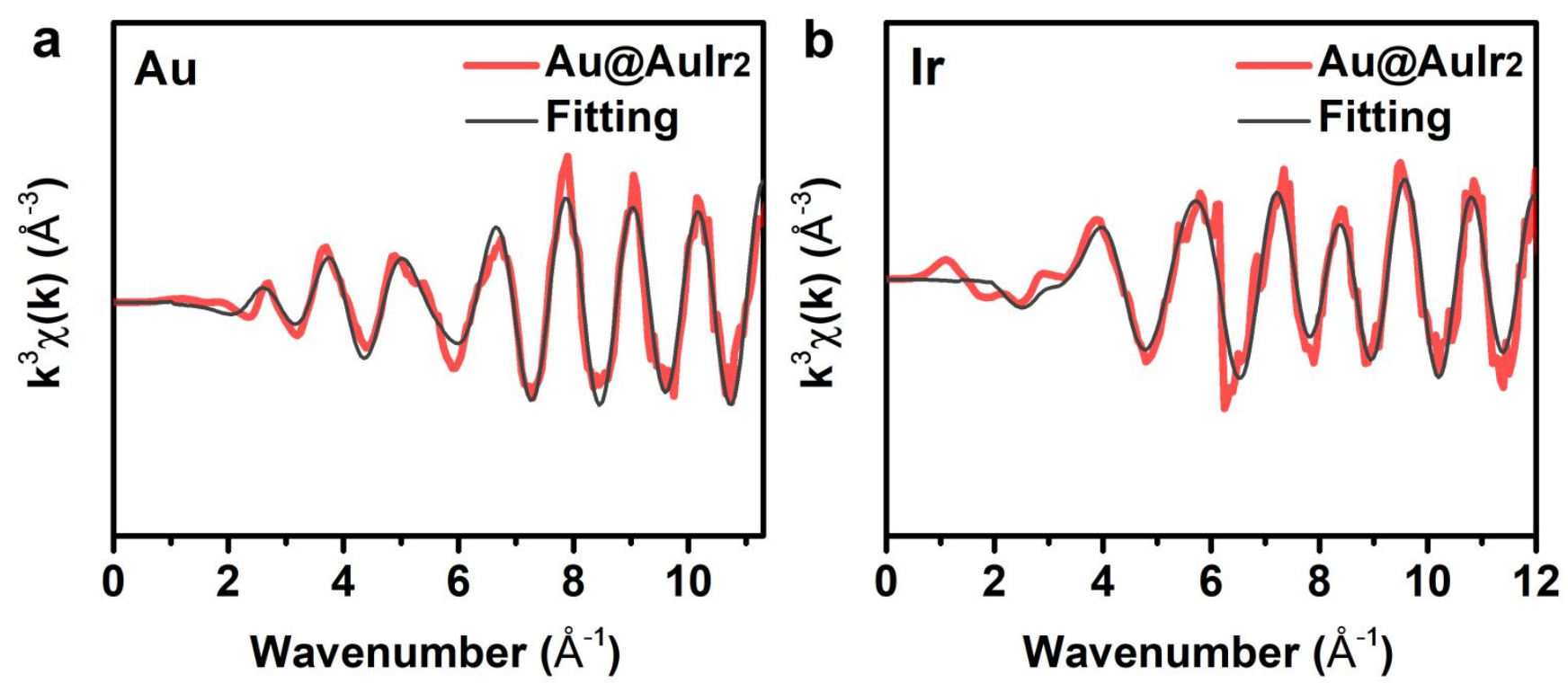

Figure S14. Corresponding $k$-weighted EXAFS spectra at (a) Au $L_{3}$-edge and (b) Ir $L_{3}$-edge collected for Au@AuIr $r_{2}$ The black lines show the fitting data of each EXAFS spectrum. 

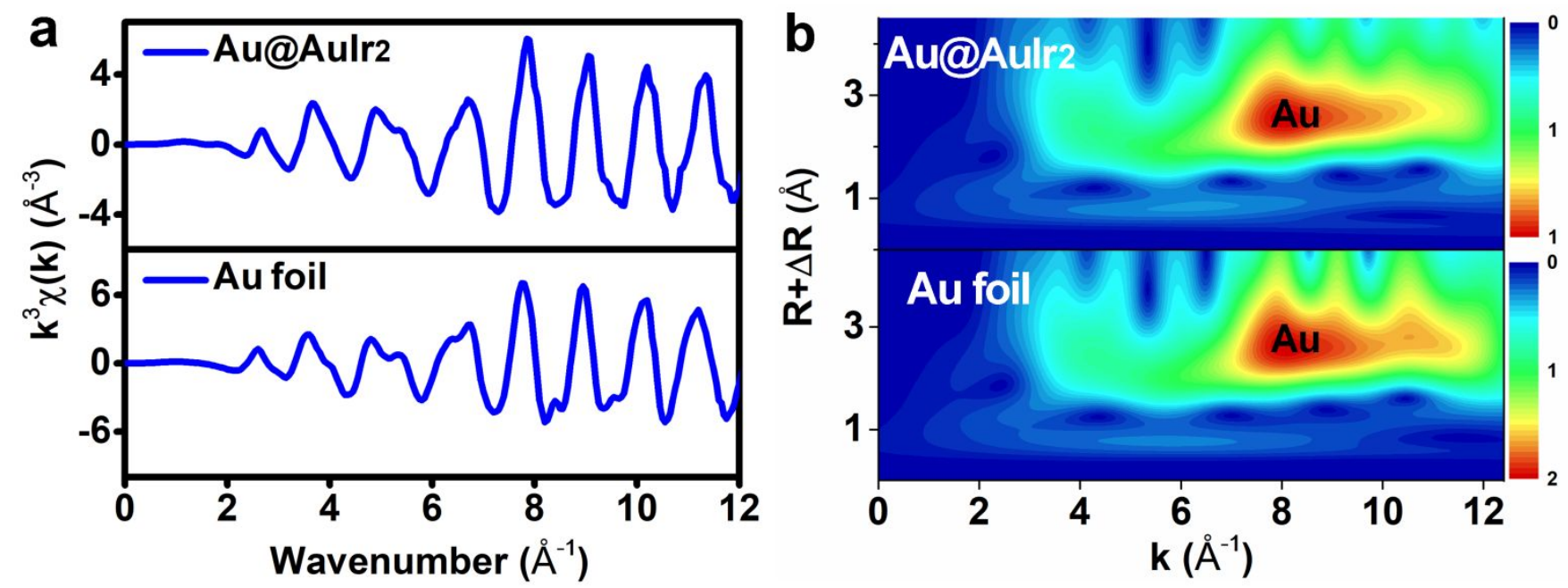

Figure S15. Wavelet transform for the $k^{3}$-weighted Au $L_{3}$-edge EXAFS signal of Au@AuIr ${ }_{2}$ and Au foil. 

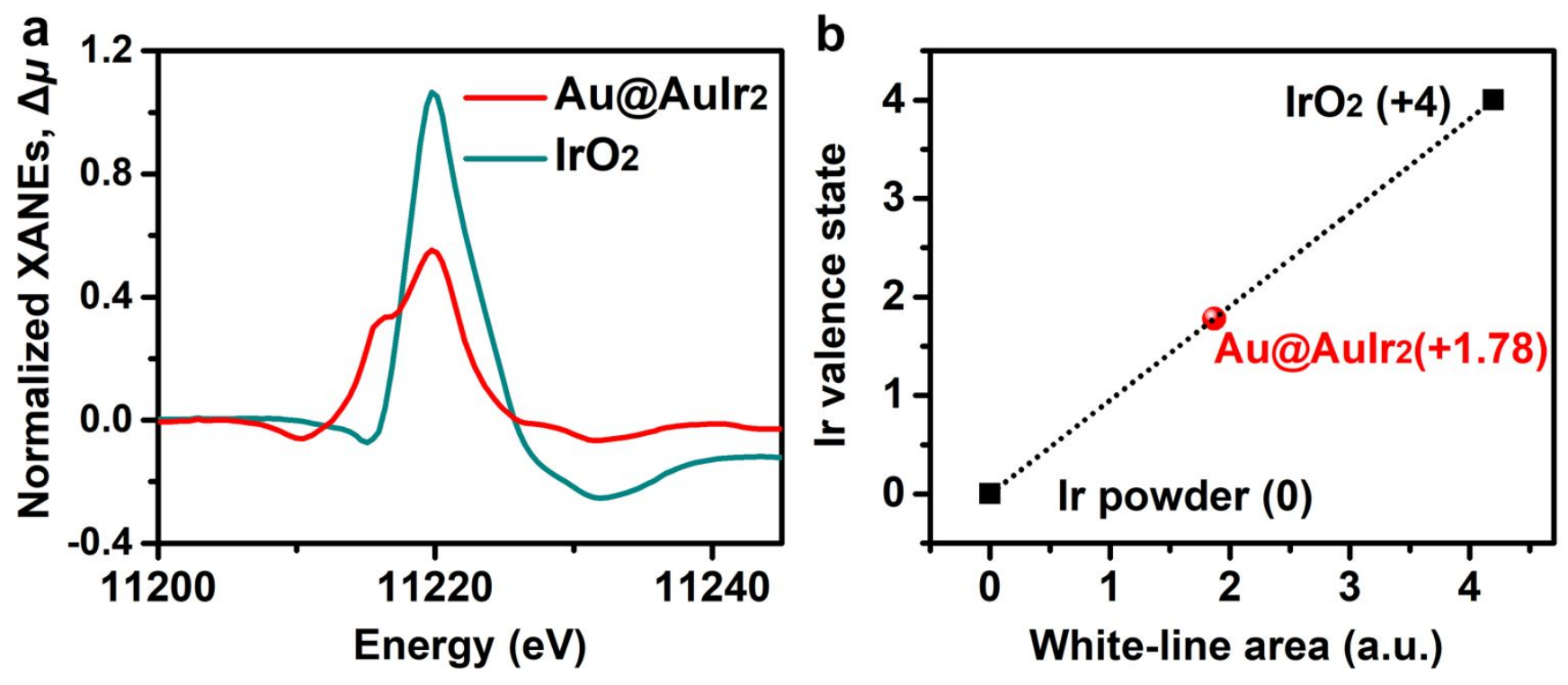

Figure S16. (a) Normalized difference spectra for Ir $L_{3}$-edge XANES using Ir powder as reference. (b) The oxidation states of Ir from $\triangle$ XANES spectra. 

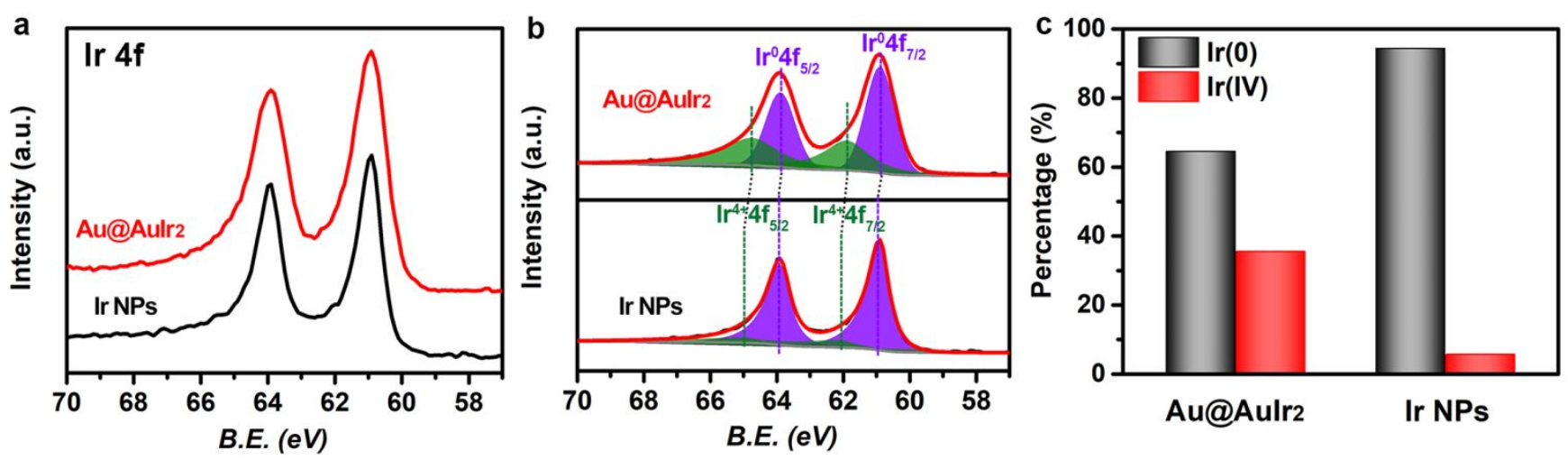

Figure S17. (a) XPS spectra of Au@AuIr ${ }_{2}$ and Ir NPs. (b) XPS spectra for the Ir $4 \mathrm{f}$ regions of Au@AuIr ${ }_{2}$ and Ir NPs: XPS raw data (black line) and fitting curves (red line). (c) $\mathrm{IrO}_{\mathrm{X}}$ percentage (estimated by XPS) of Au@AuIr $\mathrm{r}_{2}$ and Ir NPs. 


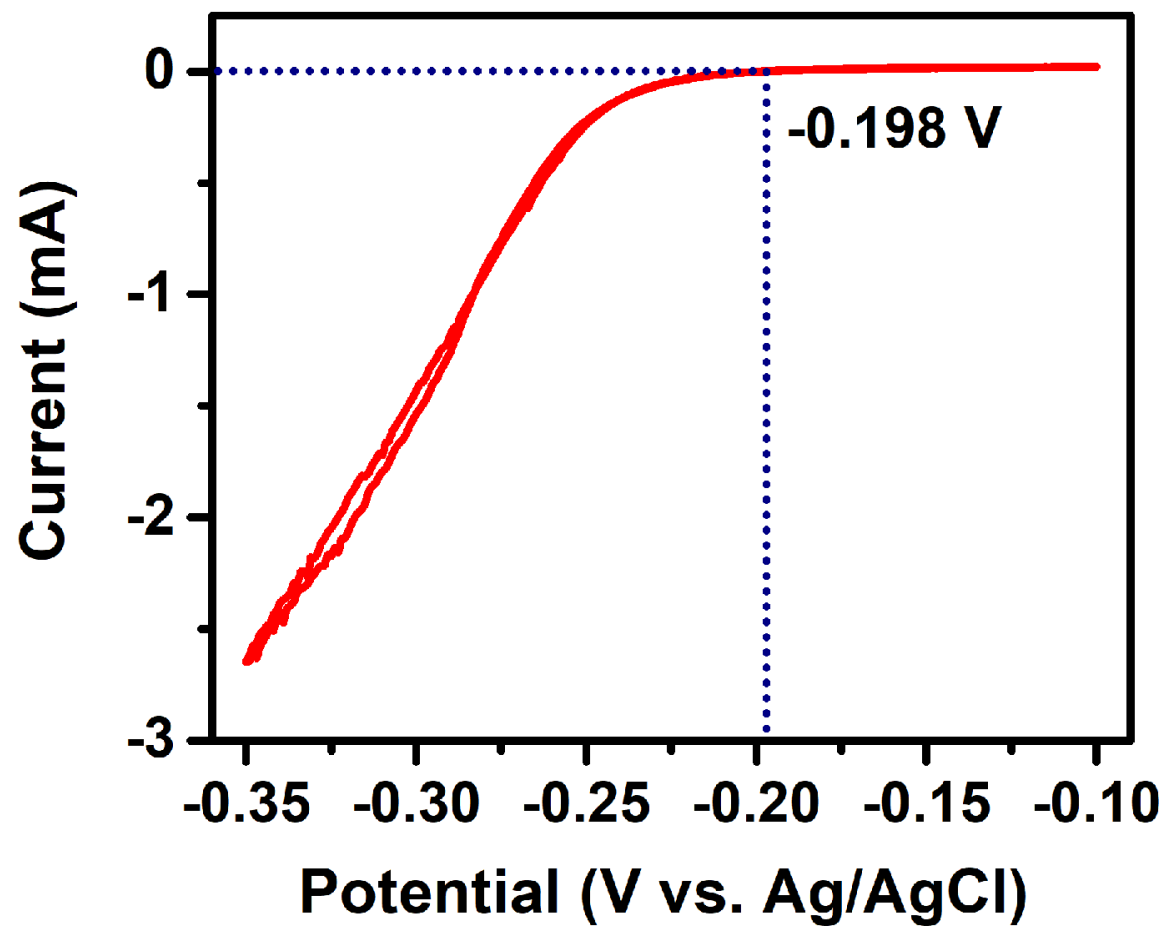

Figure S18. Calibration of the $\mathrm{Ag} / \mathrm{AgCl}$ reference electrode against the RHE. 

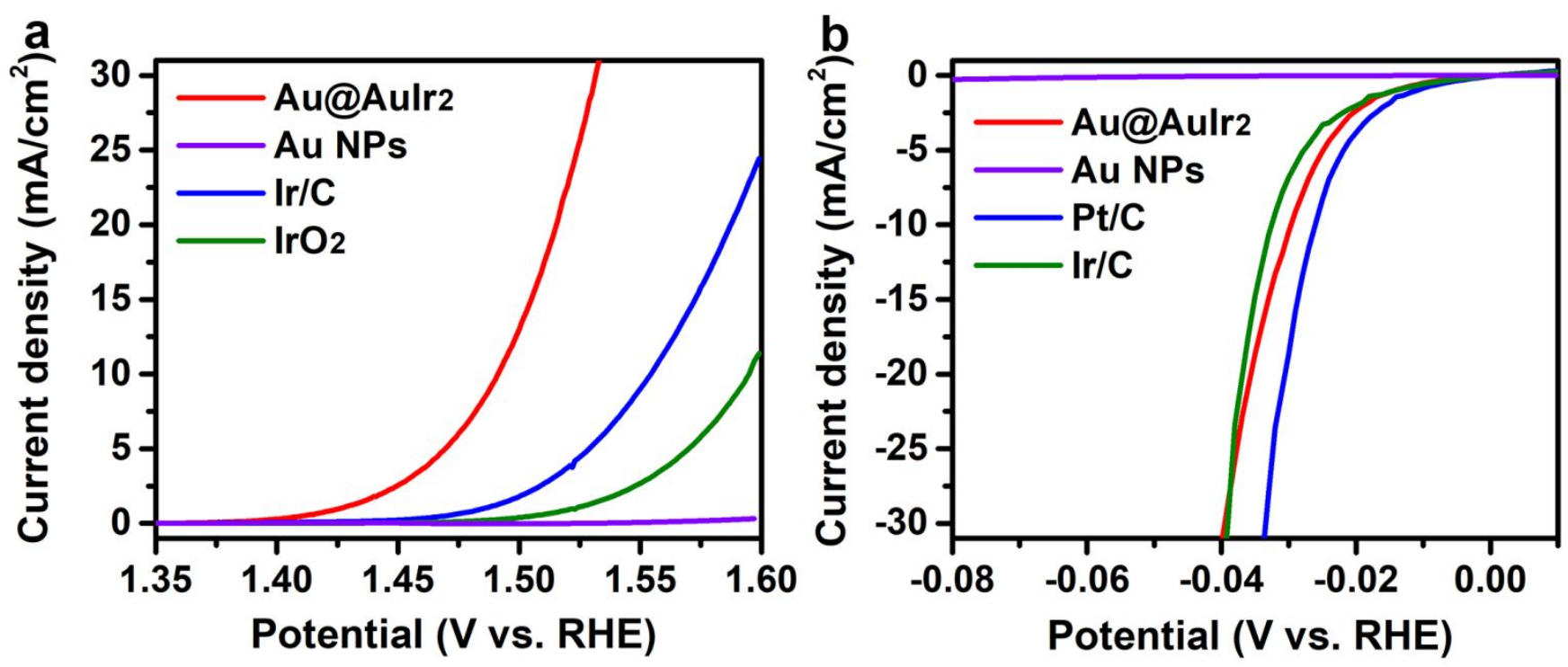

Figure S19. (a) OER polarization curves of Au@AuIr $r_{2}$, Au NPs, commercial $\mathrm{Ir} / \mathrm{C}$ and $\mathrm{IrO}_{2}$ in o.5 $\mathrm{M} \mathrm{H}_{2} \mathrm{SO}_{4}$ solution. (b) HER polarization curves of Au@AuIr ${ }_{2}$, Au NPs, commercial Pt/C and $\mathrm{Ir} / \mathrm{C}$ in $0.5 \mathrm{M} \mathrm{H}_{2} \mathrm{SO}_{4}$ solution. 

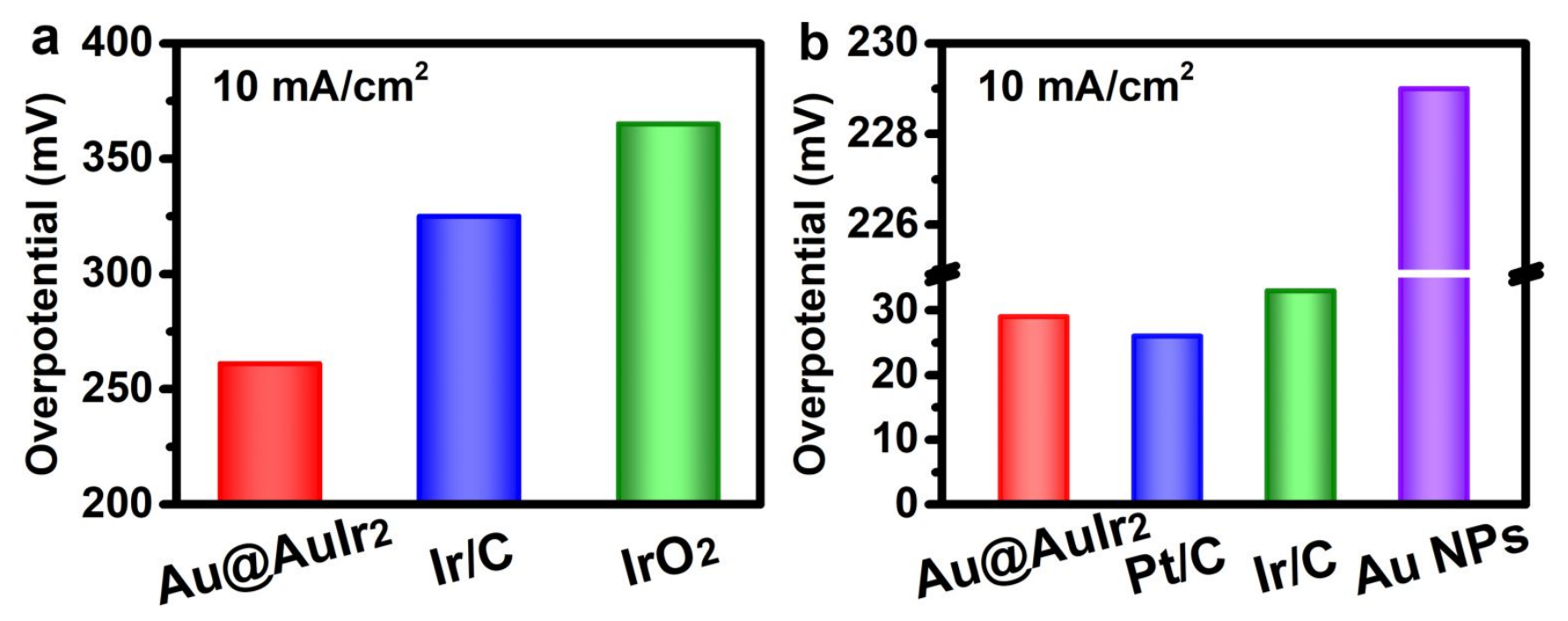

Figure S2o. The overpotentials reach to $10 \mathrm{~mA} / \mathrm{cm}^{2}$ for OER (a) and HER (b). 

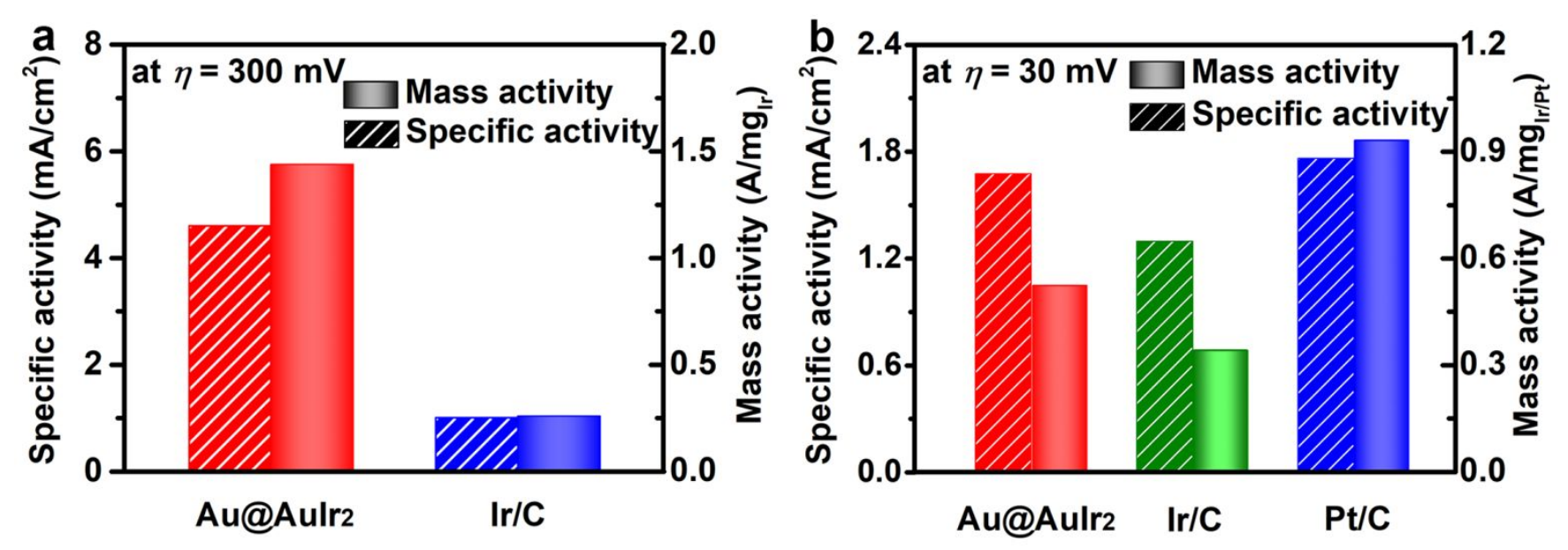

Figure S21. (a) Specific and mass activities at $\eta=300 \mathrm{mV}$ of Au@AuIr relative to the commercial Ir/C catalyst for OER. (b) Specific and mass activities at $\eta=30 \mathrm{mV}$ of $\mathrm{Au} @ \mathrm{AuIr}_{2}$ relative to the commercial $\mathrm{Ir} / \mathrm{C}$ and $\mathrm{Pt} / \mathrm{C}$ catalysts for HER. 

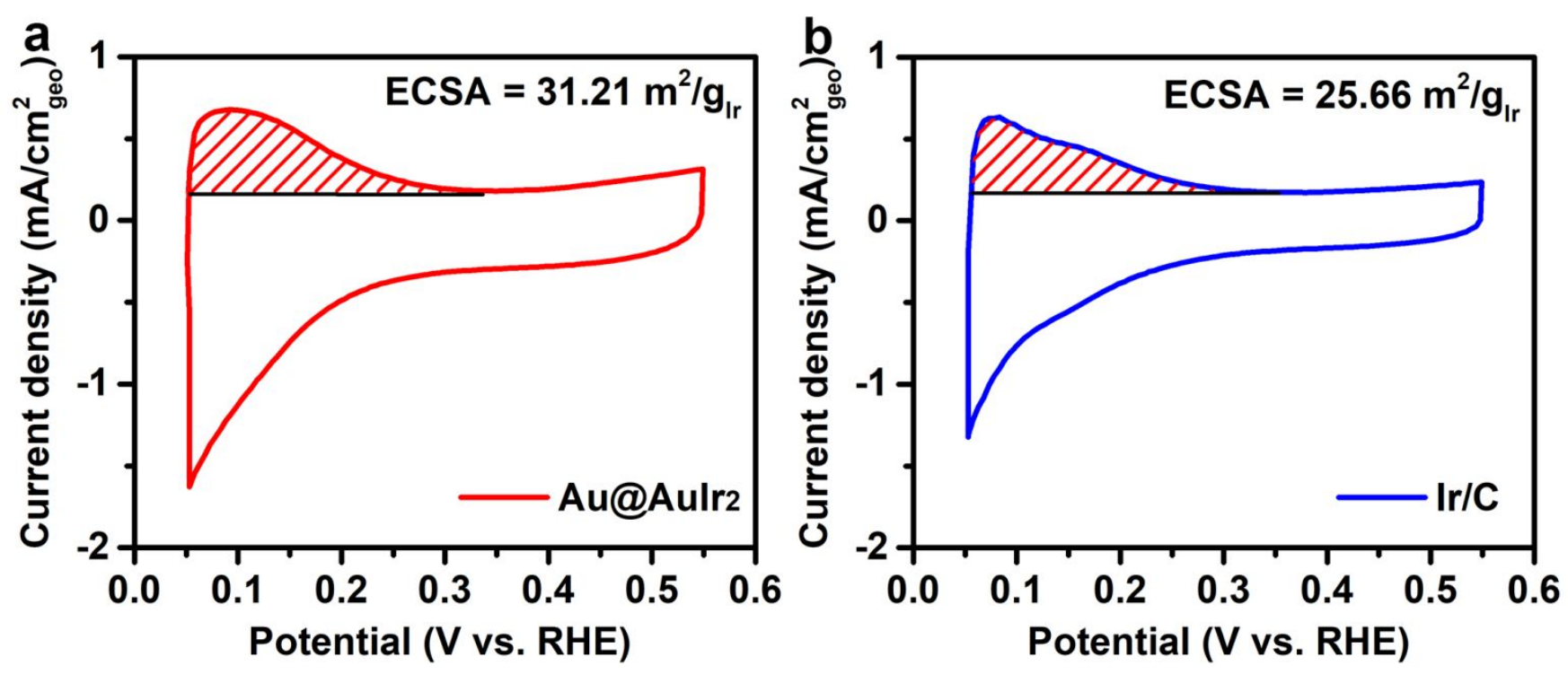

Figure S22. CV of (a) Au@AuIr ${ }_{2}$ and (b) $\mathrm{Ir} / \mathrm{C}$ in $0.5 \mathrm{M} \mathrm{H}_{2} \mathrm{SO}_{4}$ performed between 0.05 and $0.55 \mathrm{~V}$ vs RHE and corresponding specific ECSA calculated by $H_{\text {upd }}$ area. 


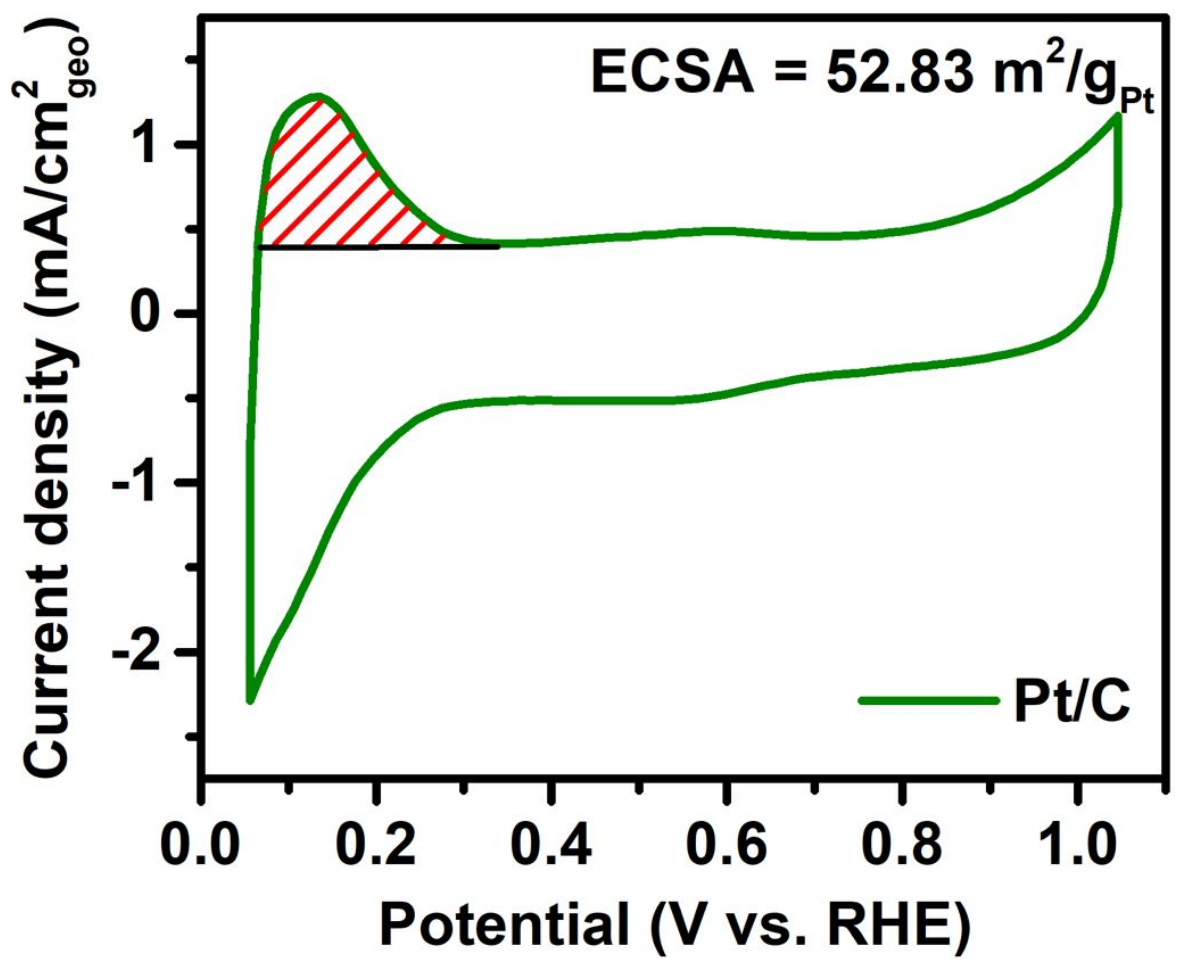

Figure S23. CV of Pt/C in $0.5 \mathrm{M} \mathrm{H}_{2} \mathrm{SO}_{4}$ performed between 0.05 and $1.05 \mathrm{~V}$ vs RHE and corresponding specific ECSA calculated by $H_{\text {upd }}$ area. 


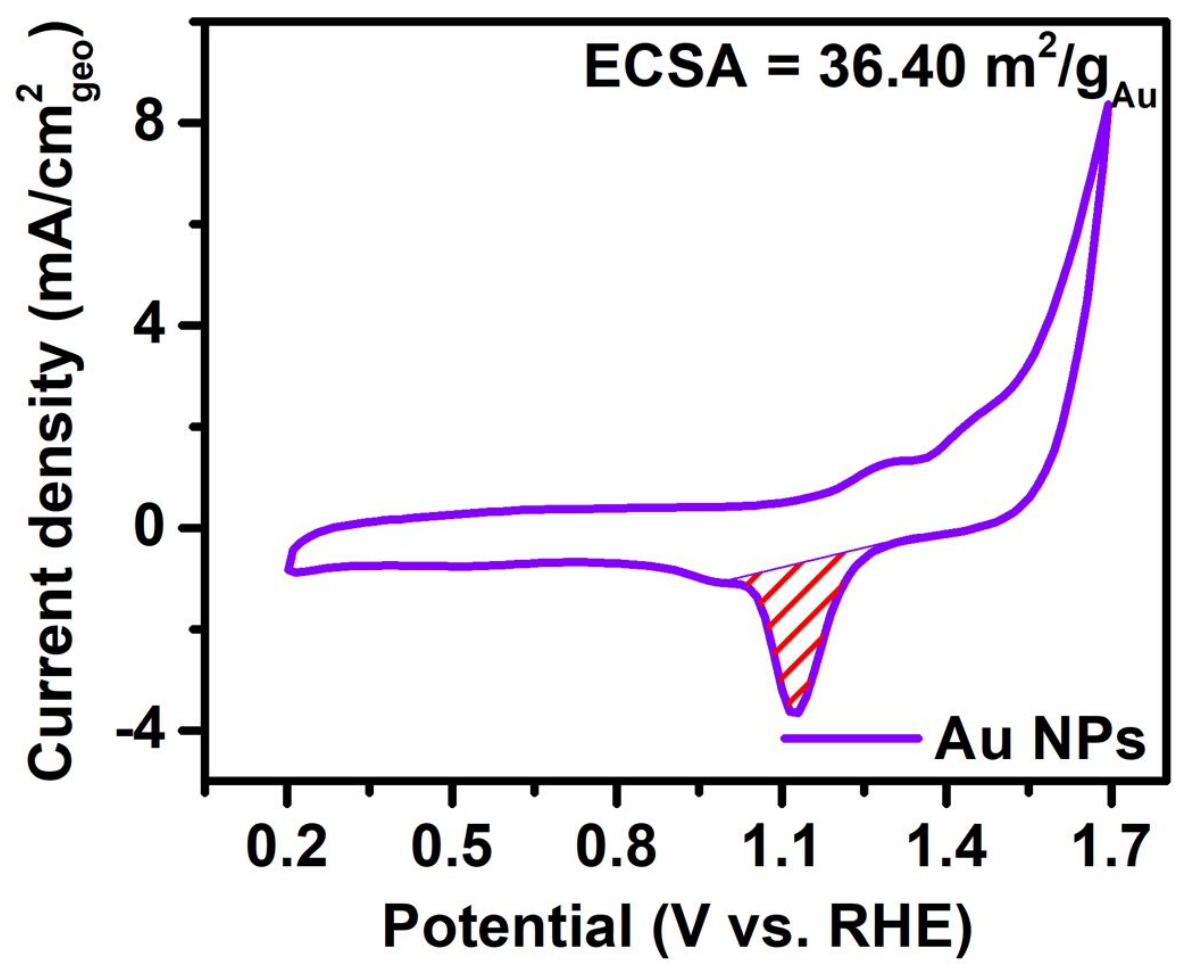

Figure S24. CV of Au measured between 0.2 and $1.7 \mathrm{~V}$ in $0.5 \mathrm{M} \mathrm{H}_{2} \mathrm{SO}_{4}$ and corresponding specific ECSA calculated by the reduction peak charge of Au oxides. 

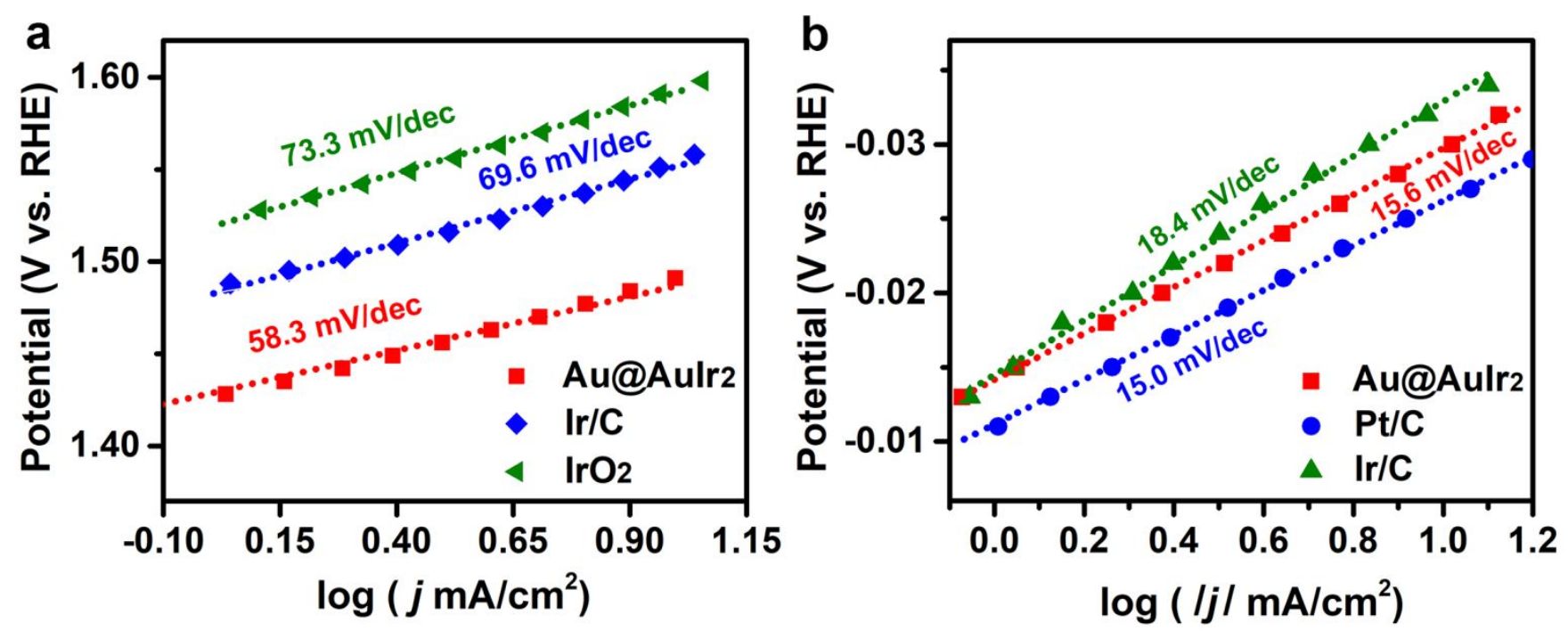

Figure S25. (a) Tafel plots derived from OER polarization curves for Au@AuIr 2 , Ir/C and $\mathrm{IrO}_{2}$; (b) Tafel plots derived from HER polarization curves for Au@AuIr, $\mathrm{Pt} / \mathrm{C}$ and $\mathrm{Ir} / \mathrm{C}$ with 9o\% iR-compensation. 

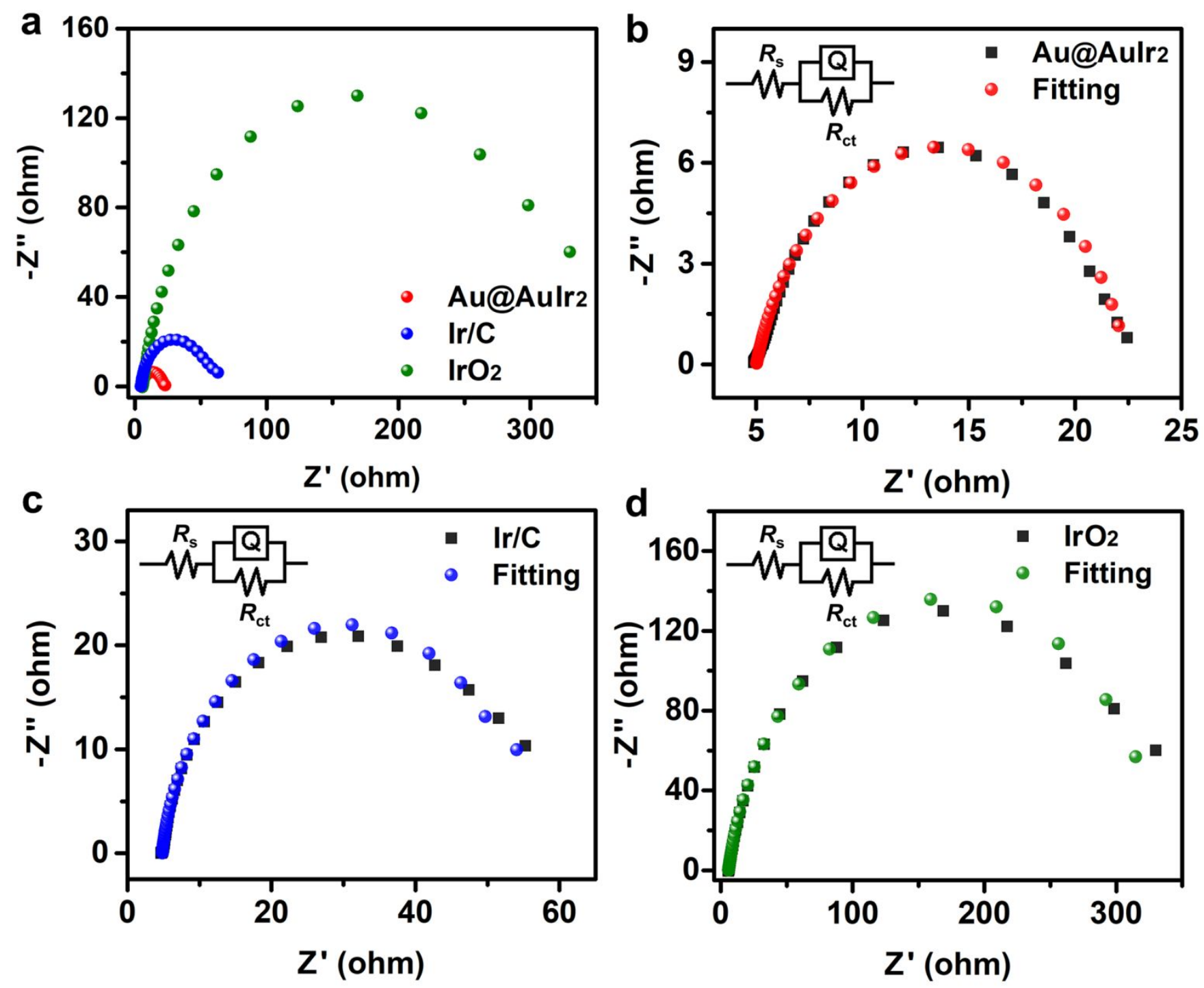

Figure S26. Nyquist plots (a) and their fitting data of Au@AuIr 2 (b) commercial $\mathrm{Ir} / \mathrm{C}$ (c) and $\operatorname{IrO}_{2}(\mathrm{~d})$ at $1.51 \mathrm{~V}$ with a frequency range of $100 \mathrm{kHz}-10 \mathrm{mHz}$. 

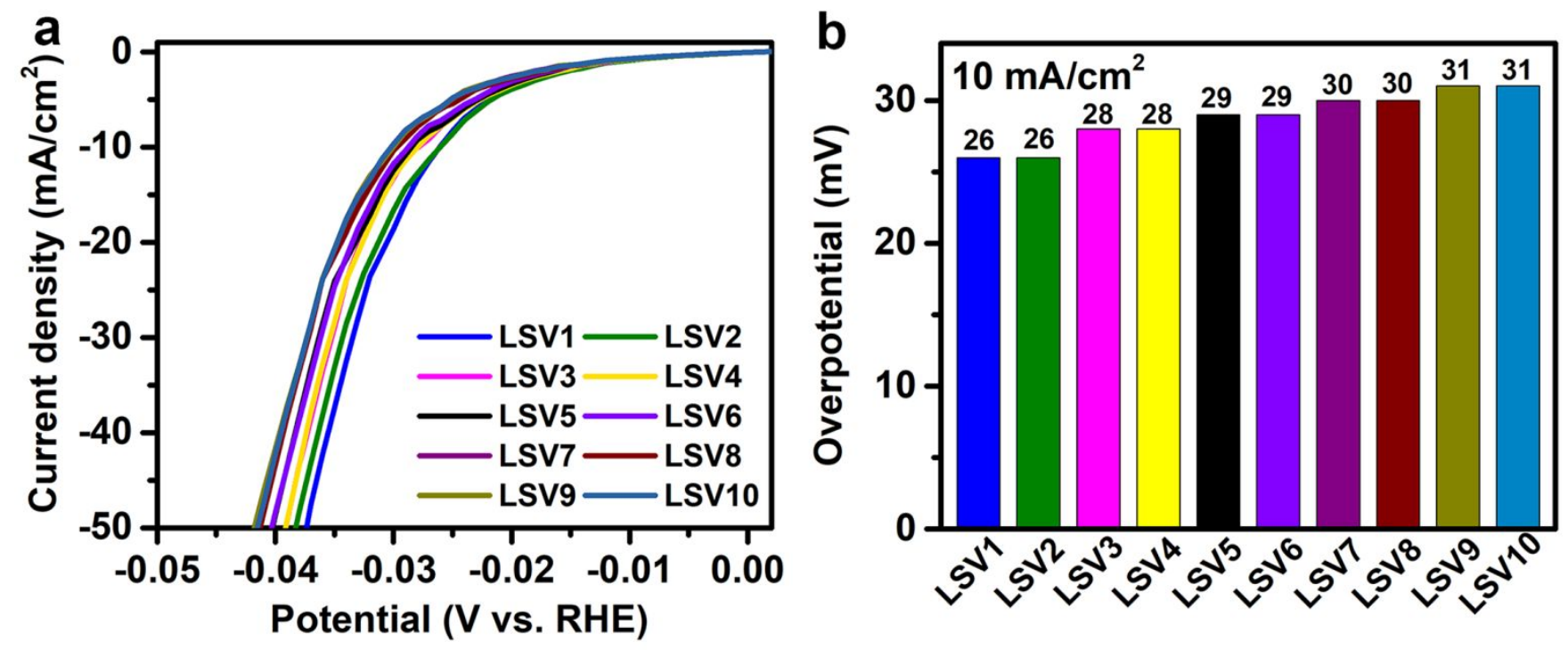

Figure S27. (a) HER polarization curves of commercial Pt/C in $0.5 \mathrm{M} \mathrm{H}_{2} \mathrm{SO}_{4}$ solution and (b) the overpotentials reach to 10 $\mathrm{mA} / \mathrm{cm}^{2}$.

The HER performance of $\mathrm{Pt} / \mathrm{C}$ is not stale until the $9^{\text {th }} \mathrm{LSV}$ scan which gives an overpotential at 10 $\mathrm{mA} / \mathrm{cm}^{2}$ in the range of $26-31 \mathrm{mV}$. 


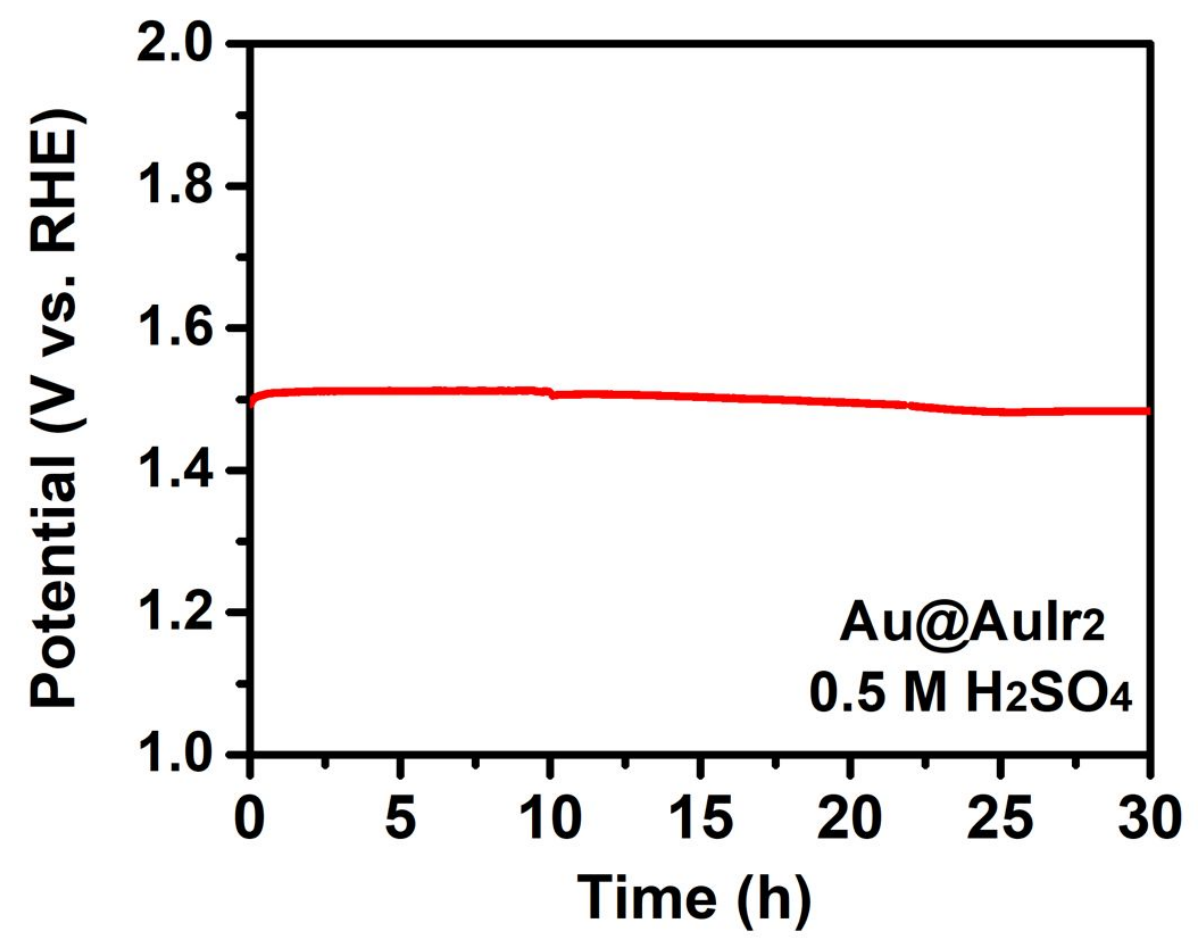

Figure S28. Chronopotentiometric test at $10 \mathrm{~mA} / \mathrm{cm}^{2}$ for OER of Au@AuIr ${ }_{2}$. 


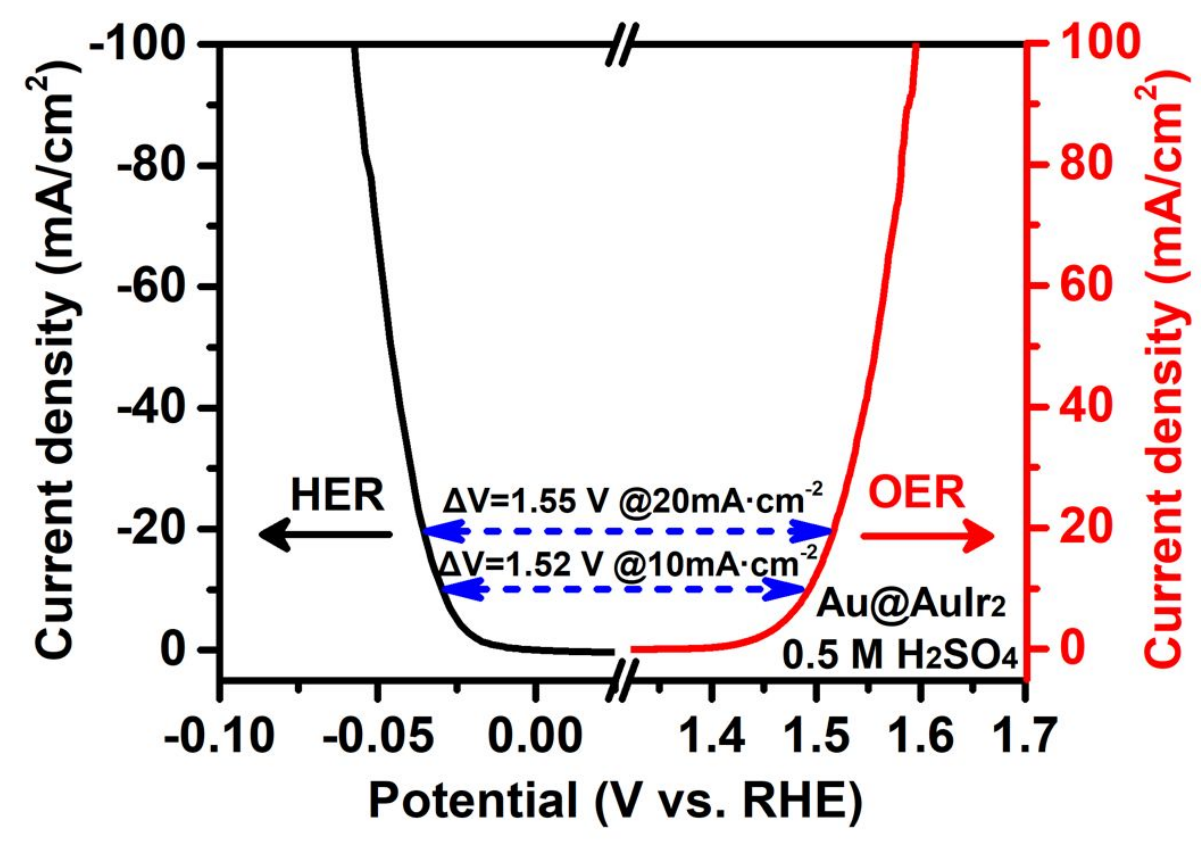

Figure S29. Polarization curves of $\mathrm{Au} @ \mathrm{AuIr}_{2}$ for HER and OER in $0.5 \mathrm{M} \mathrm{H}_{2} \mathrm{SO}_{4}$ solution at a scan rate of $10 \mathrm{mV} / \mathrm{s}$. 

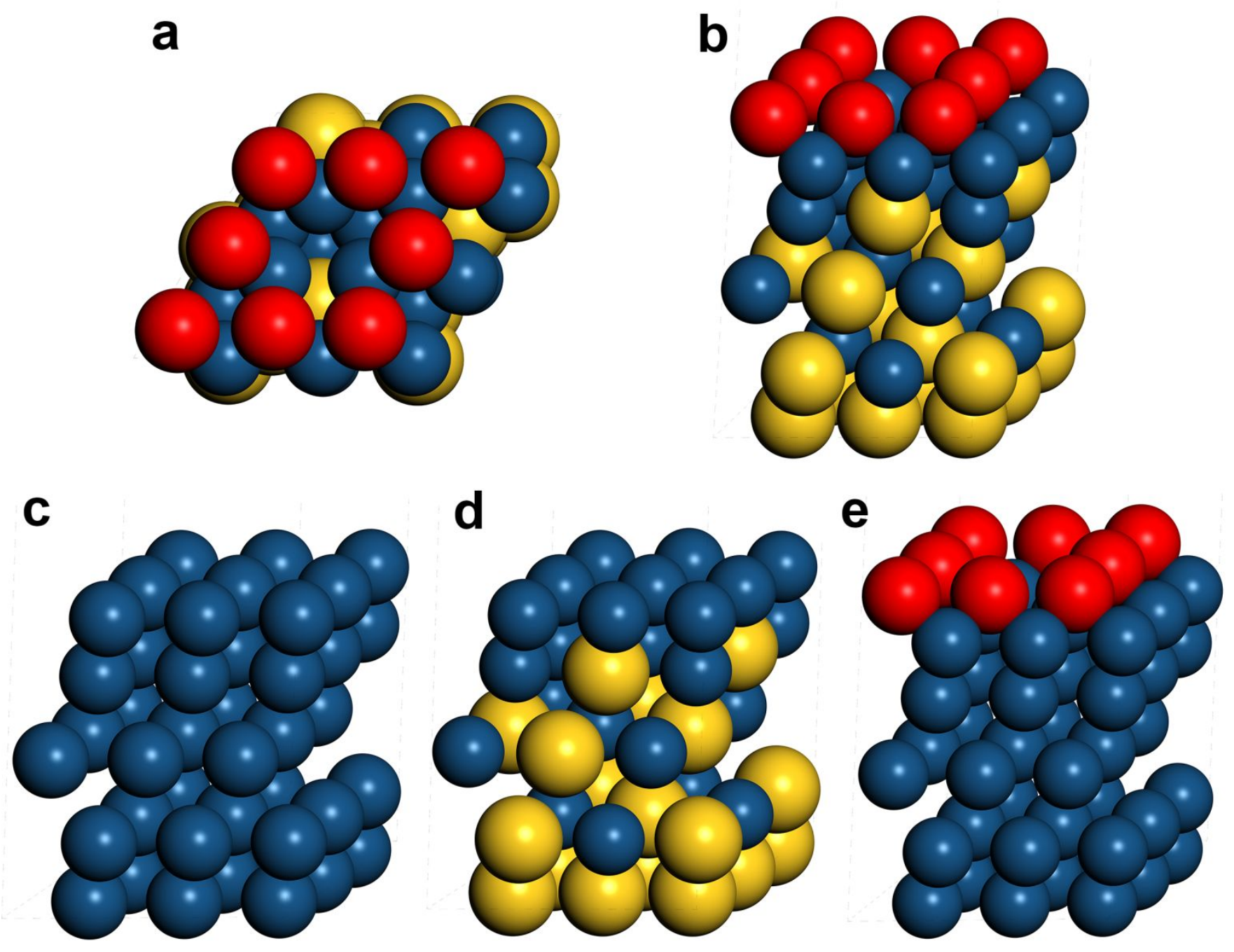

Figure S30. DFT calculation models of (a) top view and (b) side view of $A u @ A \operatorname{Arr}_{2} \mathrm{O}_{x}(111)$, (c) Ir (111), (d) $\mathrm{Au} @ \mathrm{AuIr}_{2}(111)$ and $\mathrm{IrO}_{\mathrm{x}}$ (111). 
Table S1 Fitting Results of $A u L_{3}$-Edge and Ir $L_{3}$-Edge EXAFS Data.

\begin{tabular}{|c|c|c|c|c|c|}
\hline sample & bond & $\mathrm{CN}$ & bond length $(\AA)$ & $\sigma^{2}\left(10^{-3} \AA^{2}\right)$ & r-factor \\
\hline & $\mathrm{Au}-\mathrm{Au}$ & 10.53 & 2.84 & 10.67 & 0.0098 \\
\cline { 2 - 6 } & $\mathrm{Au}-\mathrm{Ir}$ & 1.40 & 2.82 & 7.99 & 0.0098 \\
\cline { 2 - 6 } $\mathrm{Au} @$ AuIr 2 & $\mathrm{Ir}-\mathrm{Au}$ & 2.78 & 2.82 & 7.99 & 0.0082 \\
\cline { 2 - 6 } & $\mathrm{Ir}-\mathrm{Ir}$ & 5.43 & 2.69 & 6.51 & 0.0082 \\
\cline { 2 - 6 } & $\mathrm{Ir}-\mathrm{O}$ & 3.38 & 2.02 & 4.28 & 0.0082 \\
\hline $\mathrm{Au}$ foil & $\mathrm{Au}-\mathrm{Au}$ & $12.00^{*}$ & 2.86 & 8.36 & 0.0125 \\
\hline Ir (fcc) & $\mathrm{Ir}-\mathrm{Ir}$ & $12.00^{*}$ & 2.74 & -- & -- \\
\hline
\end{tabular}

$\mathrm{N}$, coordination number; R, interatomic distance; $\sigma^{2}$, Debye-Waller factor; Error bounds (accuracies) were estimated as $\mathrm{N}, \pm 10 \% ; \mathrm{R}, \pm 1 \% ; \sigma^{2}, \pm 10 \%{ }^{*}$ is fixed coordination number according to the standard crystal structure. For comparison, the expected interatomic distances of reference systems based on their standard crystal structures are presented here: $\mathrm{Ir}$ (fcc): Ir-Ir, $2.74 \AA \AA$; $\mathrm{IrO}_{2}$ : Ir-O, $2.00 \AA$; $\mathrm{Au}$ foil: $\mathrm{Au}-\mathrm{Au}, 2.86 \AA$. 
Table S2 Comparisons of OER activity between Au@Aulr ${ }_{2}$ and recently reported Ir-based catalysts in acidic electrolyte.

\begin{tabular}{|c|c|c|c|c|c|c|}
\hline Catalyst & Electrolyte & $\begin{array}{c}\eta(\mathrm{mV}) \\
\text { to } 10 \\
\mathrm{~mA} / \mathrm{cm}^{2}\end{array}$ & $\begin{array}{c}\text { Mass } \\
\text { loading } \\
\mu g_{\mathrm{Ir}} / \mathrm{cm}^{2}\end{array}$ & $\begin{array}{l}\text { Mass activity } \\
\text { at } \boldsymbol{\eta}=\mathbf{3 0 0} \mathrm{mV} \\
(\mathrm{A} / \mathrm{g})\end{array}$ & $\begin{array}{l}\quad i R \text { - } \\
\text { corrected } \\
\text { condition }\end{array}$ & Ref. \\
\hline $\begin{array}{l}\mathbf{A u} @ \\
\mathbf{A u I r}_{2}\end{array}$ & $\begin{array}{l}0.5 \mathrm{M} \\
\mathrm{H}_{2} \mathrm{SO}_{4}\end{array}$ & 261 & 20.0 & 1440 & $90 \%$ & This work \\
\hline $\begin{array}{c}\mathrm{IrO}_{\mathrm{x}} / \mathrm{Sr} \\
\mathrm{IrO}_{3}\end{array}$ & $\begin{array}{l}0.5 \mathrm{M} \\
\mathrm{H}_{2} \mathrm{SO}_{4}\end{array}$ & 270 & N.A. & N.A. & $100 \%$ & $\begin{array}{c}\text { Science } 2016,353 \\
1011-1014^{10}\end{array}$ \\
\hline $\mathbf{L i}-\operatorname{IrO}_{x}$ & $\begin{array}{l}0.5 \mathrm{M} \\
\mathrm{H}_{2} \mathrm{SO}_{4}\end{array}$ & 300 & $\begin{array}{l}50.0 \text { (cat } \\
\text {-alyst) }\end{array}$ & $\begin{array}{c}100 \\
(@ 290 \mathrm{mV})\end{array}$ & $-^{\mathrm{a}}$ & $\begin{array}{l}\text { J.Am.Chem.Soc.201 } \\
9,141,3014-3023^{11}\end{array}$ \\
\hline $\operatorname{IrNiO}_{x}$ & $\begin{array}{l}0.05 \mathrm{M} \\
\mathrm{H}_{2} \mathrm{SO}_{4}\end{array}$ & N.A. & 10.2 & 676 & ${ }^{\mathrm{a}}$ & $\begin{array}{c}\text { Nat. Catal. } \\
2018,1,841-851^{12}\end{array}$ \\
\hline $\begin{array}{c}\text { 40- } \mathrm{IrO}_{2} \\
/ \mathrm{GCN}\end{array}$ & $\begin{array}{l}0.5 \mathrm{M} \\
\mathrm{H}_{2} \mathrm{SO}_{4}\end{array}$ & 278 & $\begin{array}{c}81.0 \\
\left(\mathrm{IrO}_{2}\right)\end{array}$ & $\begin{array}{c}497 \\
(@ 320 \mathrm{mV})\end{array}$ & $95 \%$ & $\begin{array}{l}\text { Angew. Chem. Int. } \\
\begin{array}{c}\text { Ed. } 2019,58,12540 \\
-12544^{13}\end{array}\end{array}$ \\
\hline $\begin{array}{l}\mathbf{P d} @ \\
\mathbf{I r}_{4 \mathrm{~L}} / \mathrm{C}\end{array}$ & $\begin{array}{l}0.1 \mathrm{M} \\
\mathrm{HClO}_{4}\end{array}$ & 289 & 10.2 & 1500 & $95 \%$ & $\begin{array}{c}\text { Chem. Mater. 2019, } \\
\text { 31, 5867-587514 }\end{array}$ \\
\hline $\mathrm{Ir} / \mathbf{F e}_{4} \mathbf{N}$ & $\begin{array}{l}0.5 \mathrm{M} \\
\mathrm{H}_{2} \mathrm{SO}_{4}\end{array}$ & $316 \pm 5$ & 76.5 & $\begin{array}{c}116.4 \\
(@ 310 \mathrm{mV})\end{array}$ & ${ }^{\mathrm{a}}$ & $\begin{array}{c}\text { ACS Catal. 2018, 8, } \\
2615-2621^{15}\end{array}$ \\
\hline $\begin{array}{c}\mathbf{R h}_{22} \mathbf{I r}_{78} \\
/ \mathrm{VXC}\end{array}$ & $\begin{array}{r}0.5 \mathrm{M} \\
\mathrm{H}_{2} \mathrm{SO}_{4} \\
\end{array}$ & 292 & 9.8 & 1170 & - $\mathrm{a}$ & $\begin{array}{c}\text { ACS Nano 2019, } \\
13,13225-13234^{16}\end{array}$ \\
\hline $\begin{array}{c}\mathrm{CB}[6] \\
-\mathrm{Ir}_{2}\end{array}$ & $\begin{array}{l}0.5 \mathrm{M} \\
\mathrm{H}_{2} \mathrm{SO}_{4}\end{array}$ & 270 & 20.0 & 1660 & $100 \%$ & $\begin{array}{c}\text { ACS Energy Letters } \\
2019,4, \\
1301-1307^{17}\end{array}$ \\
\hline $\begin{array}{l}\text { IrW } \\
\text { NDs }\end{array}$ & $\begin{array}{l}0.1 \mathrm{M} \\
\mathrm{HClO}_{4}\end{array}$ & $\begin{array}{c}300 \\
(8.1 \mathrm{~mA} \\
\left./ \mathrm{cm}^{2}\right)\end{array}$ & 10.2 & 794 & $95 \%$ & $\begin{array}{c}\text { ACS Cent. Sci. } \\
2018,4,1244-1252^{18}\end{array}$ \\
\hline
\end{tabular}




\begin{tabular}{|c|c|c|c|c|c|c|}
\hline IrCoNi & $\begin{array}{l}0.1 \mathrm{M} \\
\mathrm{HClO}_{4}\end{array}$ & 303 & 10.0 & $\sim 700$ & $95 \%$ & $\begin{array}{c}\text { Adv. Mater. } 2017 \text {, } \\
1703798^{19}\end{array}$ \\
\hline $\begin{array}{l}\text { IrNi } \\
\text { NCs }\end{array}$ & $\begin{array}{l}0.1 \mathrm{M} \\
\mathrm{HClO}_{4}\end{array}$ & 290 & 12.5 & 1500 & $95 \%$ & $\begin{array}{l}\text { Adv. Funct. Mater. } \\
2017,27,1700886^{20}\end{array}$ \\
\hline $\begin{array}{l}\text { Au@Ir } \\
\text { NRBs }\end{array}$ & $\begin{array}{l}0.5 \mathrm{M} \\
\mathrm{H}_{2} \mathrm{SO}_{4}\end{array}$ & 296 & N.A. & $\begin{array}{c}693.9 \\
(@ 320 \mathrm{mV})\end{array}$ & N.A. & $\begin{array}{l}\text { Small, 2016, 12, } \\
\text { 3908-391321 }\end{array}$ \\
\hline $\begin{array}{c}\mathbf{R u} \\
\text { (a) } \operatorname{IrO}_{\mathrm{x}}\end{array}$ & $\begin{array}{l}0.05 \mathrm{M} \\
\mathrm{H}_{2} \mathrm{SO}_{4}\end{array}$ & 282 & $\begin{array}{l}50.0 \text { (cat } \\
\text {-alyst) }\end{array}$ & $\begin{array}{c}650 \\
(@ 320 \mathrm{mV})\end{array}$ & ${ }^{\mathrm{a}}$ & $\begin{array}{c}\text { Chem } 2019,5,445- \\
459^{22}\end{array}$ \\
\hline
\end{tabular}

N.A. The related information was not given

_a. The $i R$-corrected was adopted for these references, but the detail condition did not list in the literature. 
Table S3 Comparisons of HER activity between Au@Aulr ${ }_{2}$ and recently reported noble metal-based catalysts in acidic electrolyte.

\begin{tabular}{|c|c|c|c|c|c|}
\hline Catalyst & Electrolyte & $\begin{array}{c}\eta(\mathrm{mV}) \text { to } 10 \\
\mathrm{~mA} / \mathrm{cm}^{2}\end{array}$ & $\begin{array}{c}\text { Mass loading } \\
\mu \mathrm{g} / \mathrm{cm}^{2}\end{array}$ & $\begin{array}{c}i R \text {-corrected } \\
\text { condition }\end{array}$ & Ref. \\
\hline $\begin{array}{l}\mathrm{Au} @ \\
\mathrm{AuIr}_{2}\end{array}$ & $\begin{array}{c}0.5 \mathrm{M} \\
\mathrm{H}_{2} \mathrm{SO}_{4}\end{array}$ & 29 & $20.0 \mu g_{\text {Ir }}$ & $90 \%$ & This work \\
\hline IrCoNi & $\begin{array}{l}0.1 \mathrm{M} \\
\mathrm{HClO}_{4}\end{array}$ & 33 & $10.0 \mu g_{\text {Ir }}$ & $95 \%$ & $\begin{array}{c}\text { Adv. Mater. } 2017 \text {, } \\
1703798^{19}\end{array}$ \\
\hline $\begin{array}{c}\text { a-RuTe }_{2} \\
\text { PNRs }\end{array}$ & $\begin{array}{l}0.5 \mathrm{M} \\
\mathrm{H}_{2} \mathrm{SO}_{4}\end{array}$ & 33 & 200 & $95 \%$ & $\begin{array}{c}\text { Nat. Commun. 2019, } \\
10,5692^{23}\end{array}$ \\
\hline $\begin{array}{c}\mathbf{R u P}_{2} @ \\
\text { NPC }\end{array}$ & $\begin{array}{c}0.5 \mathrm{M} \\
\mathrm{H}_{2} \mathrm{SO}_{4}\end{array}$ & 38 & 1000 & - a & $\begin{array}{c}\text { Angew. Chem. Int. } \\
\text { Ed. } 2017,56, \\
11559-11564 .{ }^{24}\end{array}$ \\
\hline $\begin{array}{c}\text { IrCo@ } \\
\text { NC-500 }\end{array}$ & $\begin{array}{c}0.5 \mathrm{M} \\
\mathrm{H}_{2} \mathrm{SO}_{4}\end{array}$ & 24 & 285 & N.A. & $\begin{array}{c}\text { Adv. Mater. 2018, } \\
1705324^{25}\end{array}$ \\
\hline $\begin{array}{l}\mathbf{P t}_{1} / \\
\text { OLC }\end{array}$ & $\begin{array}{c}0.5 \mathrm{M} \\
\mathrm{H}_{2} \mathrm{SO}_{4}\end{array}$ & 38 & 510 & N.A. & $\begin{array}{l}\text { Nat. Energy. } 2019 \text {, } \\
\quad 4,512-518^{26}\end{array}$ \\
\hline $\mathrm{Li}-\mathrm{IrSe} \mathbf{2}_{2}$ & $\begin{array}{c}0.5 \mathrm{M} \\
\mathrm{H}_{2} \mathrm{SO}_{4}\end{array}$ & 55 & 250 & $100 \%$ & $\begin{array}{c}\text { Angew. Chem. Int. } \\
\text { Ed. 2019, 131, } \\
14906-14911^{27}\end{array}$ \\
\hline $\begin{array}{c}\mathrm{CB}[6] \\
-\mathrm{Ir}_{2}\end{array}$ & $\begin{array}{c}0.5 \mathrm{M} \\
\mathrm{H}_{2} \mathrm{SO}_{4}\end{array}$ & 54 & $20.0 \mu g_{\mathrm{Ir}}$ & $100 \%$ & $\begin{array}{l}\text { ACS Energy Letters } \\
2019,4,1301-1307^{17}\end{array}$ \\
\hline
\end{tabular}

N.A. The related information was not given

_a. The $i R$-corrected was adopted for these references, but the detail condition did not list in the literature. 
Table S4 Comparisons of overall water splitting performance between Au@Aulr 2 and recently reported noble metal-based catalysts in acidic electrolyte.

\begin{tabular}{|c|c|c|c|c|c|}
\hline Catalyst & Electrolyte & $\begin{array}{l}\text { Voltage (V) } \\
\text { @10 mA/ } \mathrm{cm}^{2}\end{array}$ & $\begin{array}{c}\text { Mass loading } \\
\mu g / \mathrm{cm}^{2}\end{array}$ & $\begin{array}{c}i R \text {-corrected } \\
\text { condition }\end{array}$ & Ref. \\
\hline $\begin{array}{l}\mathbf{A u} @ \\
\mathbf{A u I r}_{2}\end{array}$ & $\begin{array}{l}0.5 \mathrm{M} \\
\mathrm{H}_{2} \mathrm{SO}_{4}\end{array}$ & 1.55 & $20.0 \mu g_{\mathbf{I r}}$ & $90 \%$ & This work \\
\hline IrCoNi & $\begin{array}{l}0.5 \mathrm{M} \\
\mathrm{H}_{2} \mathrm{SO}_{4}\end{array}$ & 1.65 & N.A. & $95 \%$ & $\begin{array}{c}\text { Adv. Mater. 2017, } \\
1703798^{19}\end{array}$ \\
\hline $\begin{array}{l}\text { Ir }_{6} \mathbf{A g}_{9} \\
\text { NTs/C }\end{array}$ & $\begin{array}{l}0.5 \mathrm{M} \\
\mathrm{H}_{2} \mathrm{SO}_{4}\end{array}$ & 1.55 & N.A. & $95 \%$ & $\begin{array}{c}\text { Nano Energy } \\
2019,56,330-337^{28}\end{array}$ \\
\hline $\mathbf{I r} / \mathbf{G F}$ & $\begin{array}{l}0.5 \mathrm{M} \\
\mathrm{H}_{2} \mathrm{SO}_{4}\end{array}$ & 1.55 & 820 & ${ }^{\mathrm{a}}$ & $\begin{array}{c}\text { Nano Energy } \\
2017,40,27-33^{29}\end{array}$ \\
\hline $\begin{array}{l}\mathrm{CB}[6] \\
-\mathrm{Ir}_{2}\end{array}$ & $\begin{array}{l}0.5 \mathrm{M} \\
\mathrm{H}_{2} \mathrm{SO}_{4}\end{array}$ & 1.56 & $20.0 \mu g_{\text {Ir }}$ & $100 \%$ & $\begin{array}{l}\text { ACS Energy Letters } \\
2019,4,1301-1307^{17}\end{array}$ \\
\hline $\begin{array}{l}\text { IrNi } \\
\text { NCs }\end{array}$ & $\begin{array}{l}0.5 \mathrm{M} \\
\mathrm{H}_{2} \mathrm{SO}_{4}\end{array}$ & 1.58 & N.A. & without & $\begin{array}{l}\text { Adv. Funct. Mater. } \\
2017,27,1700886^{20}\end{array}$ \\
\hline
\end{tabular}

N.A. The related information was not given

_a. The $i R$-corrected was adopted for these references, but the detail condition did not list in the literature. 
Table S5 Detail information about EIS fitting data.

\begin{tabular}{|c|c|c|c|c|c|}
\hline $\begin{array}{l}\text { The equivalent } \\
\text { circuit used to fit } \\
\text { the EIS data }\end{array}$ & Sample & $\begin{array}{c}R_{\mathrm{s}} \\
\left(\Omega \mathrm{cm}^{2}\right)\end{array}$ & $\begin{array}{c}\text { CPE-Yo } \\
\left(\mathrm{F} / \mathrm{cm}^{2}\right)\end{array}$ & $\begin{array}{l}\text { CPE-O } \\
\left(\mathrm{F} / \mathrm{cm}^{2}\right)\end{array}$ & $\begin{array}{c}R_{\mathrm{ct}} \\
\left(\Omega \mathrm{cm}^{2}\right)\end{array}$ \\
\hline & $\mathbf{A u} @ \mathbf{A u I r}_{2}$ & 5.00 & $6.94 * 10^{-3}$ & $8.09 * 10^{-1}$ & 17.5 \\
\hline & $\mathbf{I r} / \mathbf{C}$ & 4.85 & $1.28 * 10^{-3}$ & $9.07 * 10^{-1}$ & 50.9 \\
\hline & $\mathrm{IrO}_{2}$ & 4.94 & $1.02 * 10^{-3}$ & $8.76^{*} 10^{-1}$ & 331.3 \\
\hline
\end{tabular}


Table S6 Dissolved amount of metals from Au@Aulr ${ }_{2}$ and Ir/C catalysts in electrolyte after the durability test examined by ICP-OES.

\begin{tabular}{|c|c|c|c|c|c|}
\hline Sample & $\begin{array}{c}\text { Durability } \\
\text { test }\end{array}$ & $\begin{array}{c}\text { Dissolved Ir } \\
(\boldsymbol{\mu g})\end{array}$ & $\begin{array}{c}\text { Dissolved } \\
\text { Au }(\boldsymbol{\mu g})\end{array}$ & $\begin{array}{c}\text { Percentage of } \\
\text { dissolved Ir } \\
\text { from the } \\
\text { initial mass }\end{array}$ & $\begin{array}{c}\text { Percentage of } \\
\text { dissolved Au } \\
\text { from the initial } \\
\text { mass }\end{array}$ \\
\hline $\mathbf{A u @ A u I r _ { 2 }}$ & $\begin{array}{c}10 \mathrm{~mA} / \mathrm{cm}^{2}, \\
40 \mathrm{~h}\end{array}$ & 1.14 & 0 & $22.8 \%$ & 0 \\
\hline $\mathbf{I r} / \mathbf{C}$ & $10 \mathrm{~mA} / \mathrm{cm}^{2}$, & 1.26 & - & $25.2 \%$ & - \\
\hline
\end{tabular}




\section{References}

1. Rudi, S.; Cui, C.; Gan, L.; Strasser, P., Comparative Study of the Electrocatalytically Active Surface Areas (ECSAs) of Pt Alloy Nanoparticles Evaluated by Hupd and CO-stripping voltammetry. Electrocatalysis 2014, 5 (4), 408-418.

2. Kresse, G.; Hafner, J., ab-initio molecular-dynamics for open-shell transition-metals. Phys. Rev. B 1993, 48 (17), 13115-13118.

3. Kresse, G.; Furthmuller, J., Efficient iterative schemes for ab initio total-energy calculations using a plane-wave basis set. Phys. Rev. B 1996, 54 (16), 11169-11186.

4. Kresse, G.; Furthmuller, J., Efficiency of ab-initio total energy calculations for metals and semiconductors using a plane-wave basis set. Comput. Mater. Sci. 1996, 6 (1), 15-50.

5. Blochl, P. E., Projector Augmented-wave Method. Phys. Rev. B 1994, 50 (24), 17953-17979.

6. Perdew, J. P.; Burke, K.; Ernzerhof, M., Generalized gradient approximation made simple. Phys. Rev. Lett. 1996, 77 (18), 3865-3868.

7. Vandersluis, P.; Spek, A. L., BYPASS: an effective method for the refinement of crystal structures containing disordered solvent regions. Acta Cryst. 1990, 46, 194-201.

8. Rossmeisl, J.; Qu, Z. W.; Zhu, H.; Kroes, G. J.; N. Rskov, J. K., Electrolysis of water on oxide surfaces. J. Electroanal. Chem. 2007, 607 (1-2), 83-89.

9. Reier, T.; Nong, H. N.; Teschner, D.; Schlögl, R.; Strasser, P., Electrocatalytic Oxygen Evolution Reaction in Acidic Environments - Reaction Mechanisms and Catalysts. Adv. Energy Mater. 2017, 7 (1), 1601275.

10. Seitz, L. C.; Dickens, C. F.; Nishio, K.; Hikita, Y.; Montoya, J. H.; Doyle, A. D.; Kirk, C.; Vojvodic, A.; Hwang, H. Y.; Norskov, J. K., A highly active and stable IrOx/SrIrO3 catalyst for the oxygen evolution reaction. Science 2016, 353 (6303), 1011-1014.

11. Gao, J.; Xu, C.-Q.; Hung, S.-F.; Liu, W.; Cai, W.; Zeng, Z.; Jia, C.; Chen, H. M.; Xiao, H.; Li, J., Breaking long-range order in iridium oxide by alkali ion for efficient water oxidation. J. Am. Chem. Soc. 2019, 141 (7), 3014-3023.

12. Nong, H. N.; Reier, T.; Oh, H.-S.; Gliech, M.; Paciok, P.; Vu, T. H. T.; Teschner, D.; Heggen, M.; Petkov, V.; Schlögl, R.; Jones, T.; Strasser, P., A unique oxygen ligand environment facilitates water oxidation in hole-doped $\mathrm{IrNiO}_{\mathrm{x}}$ core-shell electrocatalysts. Nat. Catal. 2018, 1 (11), 841-851.

13. Chen, J.; Cui, P.; Zhao, G.; Rui, K.; Lao, M.; Chen, Y.; Zheng, X.; Jiang, Y.; Pan, H.; Dou, S. X.; Sun, W., Low-Coordinate Iridium Oxide Confined on Graphitic Carbon Nitride for Highly Efficient Oxygen Evolution. Angew. Chem., Int. Ed. 2019, 58 (36), 12540-12544.

14. Zhu, J.; Lyu, Z.; Chen, Z.; Xie, M.; Chi, M.; Jin, W.; Xia, Y., Facile Synthesis and Characterization of Pd@IrnL $(n=1-4)$ Core-Shell Nanocubes for Highly Efficient Oxygen Evolution in Acidic Media. Chem. Mat. 2019, 31 (15), 5867-5875.

15. Tackett, B. M.; Sheng, W.; Kattel, S.; Yao, S.; Yan, B.; Kuttiyiel, K. A.; Wu, Q.; Chen, J. G., Reducing Iridium Loading in Oxygen Evolution Reaction Electrocatalysts Using Core-Shell Particles with Nitride Cores. ACS Catal. 2018, 2615-2621.

16. Guo, H.; Fang, Z.; Li, H.; Fernandez, D.; Henkelman, G.; Humphrey, S. M.; Yu, G., Rational Design of Rhodium-Iridium Alloy Nanoparticles as Highly Active Catalysts for Acidic Oxygen Evolution. ACS Nano 2019, 13 (11), 13225-13234.

17. You, H.; Wu, D.; Chen, Z.-n.; Sun, F.; Zhang, H.; Chen, Z.; Cao, M.; Zhuang, W.; Cao, R., Highly active and stable water splitting in acidic media using a bifunctional iridium/cucurbit [6] uril catalyst. ACS Energy Lett. 2019, 4 (6), 1301-1307.

18. Lv, F.; Feng, J.; Wang, K.; Dou, Z.; Zhang, W.; Zhou, J.; Yang, C.; Luo, M.; Yang, Y.; Li, Y.; Gao, P.; Guo, S., Iridium-Tungsten Alloy Nanodendrites as pH-Universal Water-Splitting Electrocatalysts. ACS Cent. Sci. 2018, 4 (9), 1244-1252.

19. Feng, J.; Lv, F.; Zhang, W.; Li, P.; Wang, K.; Yang, C.; Wang, B.; Yang, Y.; Zhou, J.; Lin, F.; Wang, G. C.; Guo, S., Iridium-Based Multimetallic Porous Hollow Nanocrystals for Efficient Overall-Water-Splitting Catalysis. Adv. Mater. 2017, 29 (47). 
20. Pi, Y.; Shao, Q.; Wang, P.; Guo, J.; Huang, X., General Formation of Monodisperse IrM (M = Ni, Co, Fe) Bimetallic Nanoclusters as Bifunctional Electrocatalysts for Acidic Overall Water Splitting. Adv. Funct. Mater. 2017,27 (27), 1700886.

21. Fan, Z.; Luo, Z.; Chen, Y.; Wang, J.; Li, B.; Zong, Y.; Zhang, H., Synthesis of 4H/fcc - Au@ M (M=Ir, Os, IrOs) Core - Shell Nanoribbons For Electrocatalytic Oxygen Evolution Reaction. Small 2016, 12 (29), 3908-3913.

22. Shan, J.; Guo, C.; Zhu, Y.; Chen, S.; Song, L.; Jaroniec, M.; Zheng, Y.; Qiao, S.-Z., Charge-Redistribution-Enhanced Nanocrystalline Ru@IrOx Electrocatalysts for Oxygen Evolution in Acidic Media. Chem 2019, 5 (2), $445-459$.

23. Wang, J.; Han, L.; Huang, B.; Shao, Q.; Xin, H. L.; Huang, X., Amorphization activated ruthenium-tellurium nanorods for efficient water splitting. Nat. Commun.2019, 10 (1), 5692.

24. Pu, Z.; Amiinu, I. S.; Kou, Z.; Li, W.; Mu, S., RuP2 - Based Catalysts with Platinum - like Activity and Higher Durability for the Hydrogen Evolution Reaction at All pH Values. Angew. Chem., Int. Ed. 2017, 56 (38), 11559-11564.

25. Jiang, P.; Chen, J.; Wang, C.; Yang, K.; Gong, S.; Liu, S.; Lin, Z.; Li, M.; Xia, G.; Yang, Y., Tuning the Activity of Carbon for Electrocatalytic Hydrogen Evolution via an Iridium-Cobalt Alloy Core Encapsulated in Nitrogen-Doped Carbon Cages. Adv. Mater. 2018, 30 (9), 1705324.

26. Liu, D.; Li, X. G.; Chen, S.; Yan, H.; Wang, C.; Wu, C.; Haleem, Y. A.; Duan, S.; Lu, J.; Ge, B., Atomically dispersed platinum supported on curved carbon supports for efficient electrocatalytic hydrogen evolution. Nat. Energy 2019, 4 (6), 512-518.

27. Zheng, T.; Shang, C.; He, Z.; Wang, X.; Cao, C.; Li, H.; Si, R.; Pan, B.; Zhou, S.; Zeng, J., Intercalated Iridium Diselenide Electrocatalysts for Efficient pH - Universal Water Splitting. Angew. Chem., Int. Ed. 2019, 131 (41), $14906-14911$.

28. Zhu, M.; Shao, Q.; Qian, Y.; Huang, X., Superior overall water splitting electrocatalysis in acidic conditions enabled by bimetallic Ir-Ag nanotubes. Nano Energy 2019, 56, 330-337.

29. Zhang, J.; Wang, G.; Liao, Z.; Zhang, P.; Wang, F.; Zhuang, X.; Zschech, E.; Feng, X., Iridium nanoparticles anchored on 3D graphite foam as a bifunctional electrocatalyst for excellent overall water splitting in acidic solution. Nano Energy 2017, 40, 27-33. 